\title{
HUGO DE SAN VÍCTOR: INTERIORIDAD, AMOR Y CONOCIMIENTO
}

\author{
Daniel O. Gamarra \\ Universidad Austral, Argentina
}

\begin{abstract}
RESUMEN
En Hugo de San Víctor, el amor es la raíz y el motivo fundamental del autoconocimiento. Con el conocimiento de sí no sólo procura el alma conocer lo que es, sino también y principalmente amar más. La confluencia del conocimiento y el amor expresan la estructura de la interioridad. Esta urdimbre interior es la que permite que las almas se eleven a las alturas de la mística. Sin autoconocimienbto no sería posible recibir los dones del Espíritu Santo ni la contemplación mística.
\end{abstract}

Palabras clave: Hugo de san Victor, interioridad, amor, conocimiento

\begin{abstract}
According to Hugo de San Victor, love is the sourle and the main reason of the self acquaintance. This self acquaintance does not only enable the soul to know what it is, but also and mainly to love more. The confluencia of the acquaintance and love expresses the inwardness structure. This interior warping enables the mysticism. Without the self acquaintance it would not be possible to receive neither the Holy Ghost's gifts nor mystic contemplation.
\end{abstract}

Key words: Hugo de san Victor, love, self acquaintance, inwardness

\section{INTRODUCCIÓN}

La mística medieval tiene orígenes tempranos. Es bien conocida la discusión entre especialistas sobre el inicio cronológico de la Edad Media: sobre todo por lo que se refiere a los primeros siglos, la cuestión es ampliamente debatida. A mi entender, las primeras manifestaciones de la filosofía cristiana — que coinciden cronológicamente con las últimas manifestaciones de la filosofía antigua - podrían incluirse en un conjunto historiográfico que se podría denominar tardoantigiiedad, y que comprendería tanto la última filosofía griega como los inicios de la filosofía cristiana. Podría parecer un contrasentido denominar tardoantigiiedad precisamente a las primeras manifestaciones filosóficas en el ámbito cristiano; sin embargo, esas primeras manifestaciones pertenecen todavía a un periodo antiguo de la cristiandad. La Edad Media como tal comenzaría a deslindarse y definirse a partir de la tardoantigiiedad. De todos modos, estas son a final de cuentas, cuestiones relativamente secundarias. $Y$ estas consideraciones no tienen otro fin que el de poner de manifiesto que la Edad Media tiene orígenes cristianos antiguos que no son propiamente medievales aunque 
son el germen - un germen de unas potencialidades fuera de lo común — de lo que (sin entrar en discusiones cronológicas precisas) se llama Edad Media.

Y en este sentido, ya desde los primeros siglos del cristianismo, nos encontramos con las primeras especulaciones sobre la Sagrada Escritura, con el nacimiento de la teología como ciencia y, como centro de nuestro interés en estas páginas, con la mística. En este ensayo nos ocuparemos de estudiar algunos aspectos del conocimiento de sí en Hugo de San Víctor. Sin embargo, los textos que utilizaremos para tal fin manifiestan la recepción en el siglo XII de una larga tradición que nace en los primeros siglos de la era cristiana. Tal tradición, que por otra parte es bien conocida, aparece con una notable fuerza en el pensamiento del Victoriense. De modo genérico se puede afirmar que Hugo de San Víctor tiene tres fuentes principales en su pensamiento, sobre todo por lo que se refiere a su mística: San Agustín, Escoto Eriúgena y el Pseudo-Dionisio. Hemos elegido un escrito de místical para introducirnos y analizar el tema del autoconocimiento teniendo en cuenta que en ese escrito entran en juego no solamente elementos que, por así decir, pertenecen al conocimiento y a la apetitividad natural, sino que también hay un elemento no menos importante dado por la fe. Sin embargo, una distinción metodológica estricta entre ambas fuentes, si bien es posible, acarrearía un corte artificial en el pensamiento de nuestro autor; de modo que tomaremos conjuntamente esos elementos según se vayan presentando en el texto y podremos ver así cómo se integran en una unidad espiritual que trasciende los límites del puro conocimiento natural pero que nos dan una noticia más precisa del conocimiento del sí mismo.

Por otra parte, la cuestión del autoconocimiento no se plantea solamente como el ejercicio de la operación de entender, sino que también entran en juego en el análisis de la interioridad los elementos apetitivo-afectivos; de aquí que el amor sea también una fuente de conocimiento o de autoconocimiento. Es más, el amor se presenta como la raíz y el motivo fundamental del autoconocimiento: el hombre interior no se contenta con saber cuál es la estructura gnoseológica subjetiva, sino que primariamente movido por el amor, intenta a través de la introspección, aprovechar los «resultados" de ese conocimiento para acrecentar el amor. ${ }^{2}$ Así, se establece un círculo entre el conocimiento y el amor que da cuenta de la totalidad de la interioridad o, si se quiere, de la unidad antropológica. Por ello la intimidad no es estática sino profundamente dinámica: si ese dinamismo se detuviera querría decir que ya no hay vida. ${ }^{3}$ Pero al mismo tiempo que ese movimiento es hacia el interior del hombre, el dinamismo de la interioridad lleva consigo también la necesidad de exterioridad o de exteriorización de la interioridad: aquí se presenta tanto el tema de la corporeidad como el tema del amor con toda su fuerza. El amor es un en-sí pero no exactamente un para-sí, o mejor dicho, el para-sí forma parte del en-sí que es para-otro. Así como el conocimiento puede ir variando el objeto y dirigirse hacia realidades externas o internas al sujeto, el amor, radicando en el sujeto, es como el conocimiento, apertura esencial, y tiene de propio el carácter de donación. Es decir,

1 Hugo de San Víctor, De arrha animae, Migne, PL 176, 951-970. En algunas ediciones, como citaremos más adelante, este escrito de Hugo es titulado Soliloquium de arrha animae, lo cual tiene su sentido tal como veremos.

2 Cfr. G. Dumeige, Richard de Saint-Victor el l'idée chrétienne de l'amour; P.U.F., Paris 1952.

3. Cfr. R. Yepes - J. Aranguren, Fundamentos de Antropología, EuNSA, Pamplona 1999, pp. 64 y ss. Unas páginas antes habían afirmado los autores: «La intimidad indica un dentro que sólo conoce uno mismo. El hombre tiene dentro, es parä sí, y se abre hacia su propio interior en la medida en que se atreve a conocerse, a introducirse en la profundidad de su alma» (p. 62). 
ni en el conocimiento ni en el amor hay autosuficiencia, sino que por el contrario, la apertura de la intimidad es condición indispensable para la recepción de la realidad. Y en este sentido, tanto el conocimiento como el amor tienen sentido de respuesta, ${ }^{4}$ de modo que, «lo extraño», como se refiere von Balthassar, ya no es tal, sino que resulta lo familiar al hombre precisamente porque en la autoposesión de sí mismo posee - - es- aquello que posee como forma de su propia interioridad. Veremos más adelante cómo en Hugo de San Víctor la confluencia de amor y de conocimiento son la urdimbre de la interioridad y, al mismo tiempo, el camino que Hugo traza para elevarse hasta las alturas de la mística. ${ }^{5}$

\section{LA ESCUELA DE SAN VÍCTOR}

\section{a) Los orígenes y Hugo de San Victor}

Por ser una materia conocida, seremos breves en esta sección, ya que lo que nos interesa es fundamentalmente ubicar la figura de Hugo de San Víctor en su contexto histórico. Por otra parte, no es éste un trabajo de investigación historiográfica sino que lo que nos mueve es principalmente el análisis especulativo de algunas ideas centrales de nuestro autor. ${ }^{6}$ De todos modos no se puede evitar aclarar algunos puntos que son de interés histórico y dan un marco teórico más preciso para nuestro fin.

En el año 1108, Guillermo de Champeaux que se desempeñaba como maestro en París, y donde contaba con una gran cantidad de seguidores, se retiró a la ermita de San Víctor cerca de la ciudad. A pesar de su deseado retiro de la actividad pública, al menos en las dimensiones que ésta tenía en París, fue seguido también a San Víctor por una considerable cantidad de oyentes. Con alguno de sus seguidores llegó a ser Canónigo Regular de San Agustín, y poco después, a instancias de San Bernardo, fue nombrado obispo de Châlons, en 1113. A pesar de su alejamiento, San Víctor ya era una realidad consumada, y Guillermo fue sucedido por Guilduino que continuó la línea marcada por Guillermo en cuanto al estudio y a la vida de piedad de los canónigos de la abadía. Así, la abadía de San Víctor fue tomando renombre y varias abadías y conventos adoptaron la regla de los Canónigos Regulares. ${ }^{7}$ Para la erección de là abadía, los Canónigos contaron con la ayuda de numerosas personas notables, entre ellos el mismo rey de Francia, Luis VIII, que donó una importante

4 H. Urs von Balthassar, Teológica, vol.l: Verdad del mundo, Ediciones Encuentro, Madrid 1997, p. 98: «Él (el hombre) estaría entonces encubierto ante sí mismo a fin de buscarse y encontrarse, no en sí mismo, sino en el espíritu infinito que lo creó y que es el único que es autoposesión perfecta. [...] Por otra parte el espíritu humano permanece ligado a la receptividad de una sensibilidad corporal. [...] Sólo acogiendo lo ajeno y manteniéndose abierto a lo ajeno, sólo entregado a lo extraño y sirviendo a lo extraño puede el espíritu humano reclamar su ser propio».

5 Cfr. P.J. Healy, The Mysticism of the School of St. Victor; Church History, I (1932), pp. 211-221.

6 Sobre la cuestión del misticismo en la Escuela de San Víctor hay bibliografía abundante y podemos encontrar ya en el siglo XIX e inicios del XX, textos de interés sobre el tema, como por ejemplo: Ch. Vaughan, Hours with the Mystics, V, Londres 1893; M. Inge, Christian Mysticism, Londres 1898; M. De Wulf, Histoire de la philosophie médiévale, Lovaina 1905; S. Buonamici, H. di San Vittore: saggi di studio sulla filosofia mistica del secolo XII, Alatri 1898; O. Von Hugel, The Mystical Element in Religion, London 1909; B. Underhill, Mysticism, London, 1911.

7 Entre otras figuran Santa Genoveva, en París, Wigmore, en Gales, San Agustín, en Bristol, Santa Catalina, en Waterford, Santo Tomás, en Dublín, San Pedro, en Nápoles, etc. 
suma de dinero para la construcción de la iglesia de la abadía. La tradición de estudio y de piedad iniciada por Guillermo de Champeaux fue seguida sin solución de continuidad y es así como comienzan a aparecer en San Víctor personajes que han pasado a la historia del pensamiento y de la Iglesia. Después del momento de florecimiento durante los siglos XII y siguientes, la abadía fue perdiendo prestigio y vitalidad. Siglos después estuvo implicada en el movimiento jansenista, época en que el cardenal de Larochefoucauld intentó darle nuevo esplendor aunque en vano. El fin de la abadía llegó durante la Revolución Francesa, cuando fueron vendidos los edificios y se dispersó la biblioteca. $^{8}$

Por lo que a nosotros nos interesa, Hugo de San Víctor se hace presente en la abadía cuando ésta ya gozaba de prestigio. Hugo había nacido en 1096 en Sajonia. Hijo mayor de Conrado, duque de Blankenburg, entró en el monasterio de Hamersleven a edad temprana ${ }^{9}$ y posteriormente tomó los hábitos de los Canónigos Regulares. ${ }^{10}$ Fue un primo suyo, Reinhard, que había estudiado en París con Guillermo de Champeaux, el que le dio noticia de la existencia de San Víctor y allí se dirigió hacia el 1115. En 1133 fue elegido para suceder a Tomás de San Víctor en la abadía, lugar que ocupó hasta su muerte ocurrida en 1141. Fueron los años de San Víctor momentos de intensa especulación y tarea espiritual, donde escribió numerosas obras que fueron publicadas por primera vez en Rouen por los canónigos de San Víctor en 1648. ${ }^{11}$

\section{b) Las tradiciones de San Víctor}

El pensamiento filosófico-teológico del Pseudo-Dionisio está presente en todo el correr de la filosofía y teología de la Edad Media. ${ }^{12}$ Grandes autores y autores secundarios están influidos por su pensamiento, y la lectura de sus obras principales atraviesa la historia del pensamiento desde los siglos V-VI hasta la Edad Moderna. ${ }^{13}$ En la escuela de San Víctor su influencia se hace presente de

8 Para esta época la regla y el espírtu de la abadía de San Víctor se había extendido a Brujas, Ypres, Neully, etc. Cfr. P.Bonnard, L'abbaye royale de St. Victor de Paris, París 1907; Ch. Bonneàu, Notiçe des chanoines de l'Eglise, Paris 1908.

9 Cfr. J. Taylor, The origin and early life of Hugh of St. Victor: an evaluation of the tradition, Notre Dame, Indiana 1957.

10 Cfr. L. Verheijen, La régle de saint-Augustin, 2 vol., Études Agustinienes, Paris 1967.

11 Hugonis de S. Victore canonici regularis S. Victoris Parisiensis: tum pietate, tum doctrina insignis opera omnia; tribus tomis digesta ex manuscriptis ejusdem operibus quae in Bibliotheca Victorina servantur accurate castigata et emendata, cum vita ipsius antehac nusquam edita. Studio et industria canonicorum regularium regalis abbatia $\mathrm{S}$. Victoris Parisiensis (Rothomagi 1648, fol.). De todos modos esa edición contiene escritos espúreos y que sólo la crítica posterior ha podido deslindar de los auténticos. La edición de la Patrologia latina de Migne no subsana todos los problemas de la primera edición: sin embargo, los textos auténticos en la edición de Migne son segurọs en cuanto a su redacción. Esta cuestión fue aclarada de modo prácticamente definitivo por R. Baron, Études sur Hugues de Saint-Victor, Desclée de Brouwer, Bruges 1963; también, id., Textes spirituels inedits de Hugues de Saint-Victor; Melanges de science religieuse, 13 (1956), pp. 177 y ss; id., Étude sur l'authenticité de l'oeture de H. de Saint-Victor, Scriptorium, 10 (1956), 217-238; D. van den Eynde, Essai sur la succession et la date des ecrits de Hugues de Saint-Victor, Spicilegium Pontificii Athenaei Antoniani 13, Roma 1960.

12 Cfr. H.F. Dondaine, Le corpus Dionysien de l'université de Paris au XIIle siécle, Edizioni di Storia e Litteratura, Roma 1953. Cfr. también D. Knowles, The Influence of Pseudo-Dionysius on Western Mysticism, en P. Brooks, Christian Spirituality: Essays in Honor of Gordon Rupp, SCM Press, Londres 1975, pp. 81-94.

13 No hace falta nombrar a los autores que han recibido su influencia, tarito en el esplendor escolástico del siglo XIII, como en el Renacimiento -Nicolás de Cusa, por ejemplo-, y en la mística posterior del Maestro Eckhart, J. Boehme $y$ muchos otros. 
modo especial en los dos grandes maestros del siglo XII: Hugo y su discípulo Ricardo. Hugo de San Víctor incorpora temas dionisianos especialmente en su pensamiento místico, readaptando algunas categorías del Pseudo-Dionisio a la luz de conceptos agustinianos y de otros derivados del Eriúgena. ${ }^{14}$ Hugo escribe dos comentarios al De hierachïs coelestis, que posteriormente refunde en una sola obra, alrededor de 1137. El comentario es dionisiano en los temas pero agustianiano en el tono. ${ }^{15}$ En él Hugo describe el símbolo como una colección de formas visibles que llevan a la demostración o a la visión de las invisibles: ${ }^{16}$ lo cual coincide con la idea dionisiana de que los símbolos son como un puente entre la experiencia sensible y aquello que se alcanza más allá de ella, de modo que hay - también en Hugo - una ascensión o elevación de la mente hacia lo inmaterial e invisible a través de lo visible. ${ }^{17}$ Pero, al mismo tiempo, siguiendo a San Agustín, Hugo clasifica los símbolos en naturales y en aquellos otros que pertenecen al ámbito de la gracia, que permiten la ascensión hasta Dios: ${ }^{18}$ de modo que, por una parte, adopta el tema de los grados de ascensión según el esquema dionisiano, pero, por otra parte, le da a la cuestión un contenido agustiniano. Como tendremos ocasión de ver en el análisis de De arrha animae, estos temas están presentes de un modo explícito. ${ }^{19}$

Además los intereses de Hugo de San Víctor no se limitaron a la mística, sino que se extendieron a la filosofía, a la exégesis bíblica, además de lo ya nombrado respecto a la teología y a la contemplación. El Didascalion de Hugo es una introducción completa al estudio filosófico y a la exégesis. En esta última disciplina propuso una secuencia de estudios que relacionaba los tres sentidos de la Escritura: literal, alegórico y tropológico, ${ }^{20}$ al mismo tiempo que proponía una exégesis con especial acento en el sentido literal e histórico de la Escritura. ${ }^{21}$ Su obra De sacramentis christianae fidei es considerado por muchos como una de las primeras sumas medievales; de hecho aparecen referencias explícitas en el tratamiento de los sacramentos hecho por Tomás de Aquino en la Summa theologiae. En mística, además del ya citado De arrha animae, del que nos ocuparemos, son

14 En este sentido es significativo la obra de Hugo de San Víctor Commentariorum in Hierarchian Colestem S. Dionysii Aeropagite secundum interpretationem Joannis Scoti libri x. Algunas de las obras de Hugo de San Víctor están editadas en L'oeuvre de Hugues de Saint-Victor, De institutione novitiortum. De virtute orandi. De laude caritatis. De arrha animae ; texte latin par H.B. Feiss; trad. française, introduction, notes et appendices par D. Poirel, Brepols, Turnhout 1997.

15 Cfr. R. Baron, Études sur Hugues de Saint-Victor, cit., p. 133.

16 Cfr. Hugo de San Víctor, Commentarium, PL 175, 941.

17 Cfr. Hugo de San Víctor, De scripturis et scriptoribus, PL 175, 12.

18 Los símbolos de la gracia están centrados sobre todo en la imagen de Cristo y en la Sabiduría divina. Cfr. G. Zinn, De gradibus ascensiontm: The Stages of Contemplative Ascent in Two Treatises on Noah's Ark by Hugh of St. Victor, Studies in Medieval Culture, 5 (1975), pp. 61-79. La teología que desarrollaron los Padres de los primeros siglos de la Iglesia, y los de la época Escolástica, no dispuso de una expresión general que agrupara estas últimas realidades. Hugo de San Víctor trató los temas escatológicos en su obra principal De Sacramentis Christianae Fidei, bajo los títulos de Fine Saeculi y De Statu Finalis Iudicii; Santo Tomás de Aquino, por su parte, los incluyó en el suplemento de la Summa theologiae.

19 Cfr. H. van Ivanka, Zum Problem des christiches Neupaltonismus, Scholastik, 31/3 (1956), pp. 398-421, estudio de interés por lo que se refiere al contexto general del neoplatonismo en el que se mueve también Hugo de San Víctor.

20 Cfr. G. Zinn, Los canónigos regulares, en B. McGinn - J. Meyendorff, Espiritualidad cristiana, vol. I: Desde los origenes al siglo XII, Lumen, Buenos Aires 2000, pp. 237-247.

21 Cfr. R. Kimberly, Memory and History in Hugh of St. Victor's Scriptural Program, University of Wisconsin, Oshkosh 1997. 
de suma importancia De archa Noe morali y De archa Noe mystica. En estos dos tratados Hugo de San Víctor toma el arca como un símbolo estructural de las etapas de la búsqueda mística y del despliegue de la historia sagrada. La experiencia contemplativa representa la conciencia humana original, interior y no-discursiva de la presencia de Dios. En cuanto creados, los hombres tienen tres ojos: el del entendimiento para ver las cosas divinas; el ojo de la razón para ver el sí mismo interior y el ojo del sentido para observar el mundo. En la caída por el pecado el ojo del entendimiento fue enceguecido, la razón debilitada y sólo el sentido permaneció intacto. De ese modo, la imagen interior de Dios quedó como un espejo oscurecido por el pecado que puede ser limpiado por la disciplina de manera que el ojo del entendimiento puede contemplar nuevamente la imagen de Dios en la interioridad del sujeto.

Las etapas de la mística son tres para nuestrio autor: extática, unificante y transformadora. ${ }^{22}$

Así, la primera etapa de cognición o pensamiento, lleva a contemplar el relato de la creación (Génesis 1,1$)$ y de ese modo se purifica para leer de nuevo el libro del mundo creado. La meditación, que Hugo entiende como una atención concentrada en un solo asunto y como un estado de reflexión apartada e interiorizada, comienza a rehacer la interioridad rota por el pecado. Por último, la contemplación es simbolizada por un artesano que funde los fragmentos del hombre roto y desvinculado de Dios, con la llama del amor divino. En los dos escritos De archa, Hugo presenta múltiples accesos a la contemplación: el éxtasis, Ia restauración de la imagen-semejanza perdida ${ }^{23}$ y la unificación con Dios. En la primera Homilía sobre el Eclesiastés ${ }^{24}$ presenta el tema de la unidad a través de la metáfora de la madera que arde: el alma pensante, afirma Hugo, es semejante a un fuego de madera verde donde hay mucho humo y poco fuego. En la meditación el humo se aclara y las llamas comienzan a ascender; con la contemplación la llama arde más brillantemente hasta que en el fuego puro del amor, vuelta hacia el interior del sujeto, Dios es conocido verdaderamente como el que es todo en todo.

Con estos elementos estamos en condiciones de afrontar el análisis de De arrha animae, ya que las ideas presentadas hasta aquí de modo más bien sumario, aparecen de modo particular en este escrito de Hugo de San Víctor ${ }^{25}$ que nos conducirá al análisis de algunos aspectos de la subjetividad. De todos modos antes de introducirnos en la cuestión que nos interesa, me parece de provecho considerar brevemente el juicio de E. Gilson sobre la filosofía y teología del siglo XII, para completar el cuadro que se ha delineado hasta el momento.

22 En este tema se presenta otra vez la influencia de San Agustín y del Pseudo-Dionisio que habían presentado la cuestión también de modo tripartito: purificación, iluminación, perfección.

23 Cfr. M.L. Fuehrer, The Principle of Similitude in Hugh of Saint Victor's Theory of Divine Illumination, American Benedictine Review, 30 (1979), pp. 80-92. Cfr. también G. Zinn,, De gradibus ascensionum: The Stages of Contemplative Ascent in Two Treatises on Noah's Ark by Hugh of St. Victor, cit.

24 Cfr. Hugo de San Víctor, Homiliae in Ecclesiastem, l; PL 175, 117.

25 Un tema que no tocaremos es el de la centralidad Trinitaria de la reflexión de Hugo de San Víctor; aunque es de suma importancia en la estructuración de su pensamiento y de su obra, este tema nos llevaría por caminos diversos a lo que nos proponemos en estas páginas. Para esto, cfr. M.T. Clark, La Trinidad en el cristianismo latino, en B. McGinn - J. Meyendorff, Espiritualidad cristiana, vol. I: Desde los origenes al siglo XII, cit., pp. 295-308; también, L. Bouyer, A History of Christian Spirituality, Seabury, Nueva York 1982; E. Reinhardt - J.I. Saranyana, La configuración de la ciencia teológica. De Hugo de San Víctor a Tomás de Aquino, Veritas 43/.171 (1998), pp. 549-562 (Universidad de Portoalegre, Brasil). 


\section{c) Un juicio sobre el siglo XII}

De Hugo de San Víctor escribe Gilson: «Espíritu vasto y lúcido, se esfuerza por recoger en sus obras lo esencial de las ciencias sagradas y profanas, pero para orientarlas a la contemplación de Dios y al amor». ${ }^{26}$ En efecto, estos juicios nos centran perfectamente en el modo de pensar y en la formación intelectual de Hugo de San Víctor. Todavía, en épocas de Hugo, no habían hecho entrada en occidente la filosofía aristotélica y la filosofía árabe, de allí que las fuentes del pensamiento de San Anselmo, los Victorinos, Gilberto de la Porrée y otros, tiene un claro corte neoplatónico y agustiniano. Si bien respecto a San Agustín cambia el estilo puesto que en el siglo XII encontramos un modo de pensar y de decir menos retórico, más seco o más técnico, todavía resuenan en este siglo las enseñanzas de la patrística con toda su carga neoplatónica pero con un modo de presentar los temas que ya anuncia la metodología de los grandes maestros del siglo XIII.

De alguna manera Aristóteles está presente en la discusión sobre los universales —en la que Hugo de San Víctor no entra de modo explícito- y en cierta concepción de la naturaleza, presintiendo - como afirma Gilson - la física aristotélica. A su vez, la tradición agustiniana presente en el siglo XIII sería muy difícil de explicar y comprender sin los desarrollos del siglo anterior, de la misma manera que el florecimiento de las escuelas del 1100 preanuncian la creación de la Universidad de París. Hay claramente un humanismo religioso que se expresa no sólo en la filosofía y en la teología, sino también en el arte, especialmente en la cultura literaria -en la que se conservaba la tradición de la antigüedad clásica- y en la arquitectura donde se pone de manifiesto un especial gusto por las formas. Es el siglo del nacimiento del gótico en Cluny. «No es un humanismo de la forma lo que encontramos en el siglo XII, sino este humanismo más profundo que rehúsa sacrificar ningún valor espiritual y humano (...)».27

Hay, sin embargo, un desconocimiento amplio de las ciencias de la naturaleza: aunque encontramos poetas que cantan a la naturaleza, no hay pensadores que la observen desde una óptica más científica; en este sentido, el siglo XIII representa un avance considerable. «Para un pensador de este tiempo, conocer y explicar una cosa consiste siempre en mostrar que esa cosa no es lo que parece ser; que es símbolo o el signo de una realidad más profunda; que anuncia o significa otra cosa». ${ }^{28}$

Así nos encontraremos con estos matices e ideas en el pensamiento místico de Hugo de San Víctor, que además de su originalidad manifiesta que es un teólogo y filósofo de la época en que vivió. El siglo XII se nos presenta, pues, como uno de los periodos decisivos en el conocimiento de la psicología del hombre interior. Hay abundancia de tratados que ponen de manifiesto la complejidad de los movimientos de los sentimientos y del corazón, centrados fundamentalmente en Ia vida interior definida sobre todo por una vida amorosa: no es posible que la vida del corazón se realice fuera de la perspectiva del amor.

26 E. Gilson, La filosofia en la Edad Media, Gredos, Madrid 1972, p. 283. Y continúa unas líneas más adelante: «Se puede ser un místico elevado sin saber leer ni escribir; se puede ser un místico elevado, más o menos instruido, sin integrar el propio saber en la vida mística; y se puede ser un místico muy instruido y deseoso de transformar el saber mismo en contemplación. Hugo de San Víctor pertenece a este último grupo (...)» (ibid.).

27 E. Gilson, ibid., p. 319.

28 E. Gilson, ibid., p. 320. 


\section{INTERIORIDAD, AMOR, CONOCIMIENTO}

\section{a) «De arrha animae»: ¿soliloquio o diálogo?}

El texto de De arrha animae de Hugo de San Víctor se presenta como un diálogo entre dos personajes: el hombre (homo) y el alma (anima), donde es el hombre el que lleva el peso del diálogo, hablando con su alma y haciéndola reflexionar sobre su propia realidad. En alguna edición, el texto ha sido titulado Soliloquium de arrha animae. ${ }^{29}$ El motivo de este cambio de título tiene su motivo principal en el mismo texto. En efecto escribe Hugo en las líneas introductorias: «Soliloquium dilectionis, quod de Arrha animae inscriptum est, nisi charitati vestrae, ut discatis ubi vos oporteat verum amorem quaerere, et quemadmodum debeatis corda vestra spiritualium studio meditationum ad superna gaudia excitare». ${ }^{30}$ De este modo, los dos títulos son posibles y sobre ello se puede hacer una breve reflexión. En efecto, si un diálogo es presentado - en este caso por el mismo autorcomo un soliloquio, estamos en presencia de un planteamiento que nos habla ya de algunos conceptos fundamentales que atraviesan la totalidad del texto: el hombre se presenta como el todo antropológico, como el sí mismo, mientras que su alma es objetivada como parte dialéctica y, en la finalidad de nuestro autor, como la parte más débil y, a la vez, la más decisiva para la constitución de la integridad de la interioridad.

Cuando San Buenaventura cita este texto de Hugo de San Víctor, lo hace dentro de este contexto, ${ }^{31}$ ya que se refiere a la similitud que debe alcanzar el hombre respecto a su modelo; pero se trata de todo el hombre. Pudiera parecer que Hugo en DAA considera al alma como a un ser débil, desorientado, desalentado por momentos, o bien entusiasmado por el discurso del hombre. En realidad, en todo momento Hugo está refiriéndose a la totalidad del hombre aunque centra el discurso en la metanoia que debe cumplir el alma para que todo el hombre alcance las alturas del amor. ${ }^{32} \mathrm{En}$

29 Hugo von St. Victor, Soliloquium de Arrha Animae. De Vanitate Mundi; Herausgegeben von K. Müller. KIT, Bonn 1913.

30 Hugo de San Víctor, De arrha animae, PL 951. De aquí en más nos referiremos a este texto con DAA, seguido de la numeración de la columna de la edición de Migne, vol. 176. Aprovechamos esta nota para dar noticia de otras ediciones más actuales de escritos de Hugo de San Víctor de las que algunas incluyen el texto que nos interesa y otras no, pero que pueden ser de interés para una consulta más completa. Hughes de Saint-Victor, Le Gage des Divines Fiançailles (De Arrha Animae), traduit et annoté par M. Ledrus, Brujas 1923; Hugh of St. Victor, Didascalicon: De Studio Legendi - A Critical Text. Edited by C. H. Buttimer. Studies in Medieval and Renaissance Latin, vol. 10, Catholic University of America Press, Washington 1939; Hugonis de sancto Victore, Didascalion. De Studio Legendi. A Critical Text by C. H. Buttimer; SMRL, Washington 1939; Hugh of Saint Victor, Selected Spiritual Writings, Faber and Faber, Londres 1962; Hugh of St. Victor, Didascalicon: a Medieval Guide to the Arts, Columbia University Press, Nueva York 1961; P.G. Dalché (ed.), La "Description mappe mundi" de Hugutes de Saint-Victor: texte inédit avec introduction et commentaire, Études Augustiniennes, París 1988; G. Hardarson, Littérature et spiritualité en Scandinavie médiévale. La traduction norroise du De arrha animae de Hugues de Saint-Victor. Étude historique et édition critique (Bibliotheca Victorina, V), Paris-Turnhout, Brepols, 1995; B. Feiss, L'cuvre de Hugues de Saint-Victor; I: De institutione novitiorum; De virtute orandi; De laude caritatis; De artha animae, Brepols, París 1997.

31 San Buenaventura, Commentarium in libros Sententiarum, L. II, Prologus, en Opera Omnia S. Bonaventurae, vol. II, p. 4, Quaracchi, Ad Claras Aquas 1882. Hugo de San Víctor es nombrado tambien por Dante Alighieri, Divina comedia, Paradiso, Canto XI, 133, donde es nombrado entre los grandes teólogos, aunque Dante no hace referencia a ninguna de sus obras.

32 Sobre el vocablo arrha se puede consultar: Hilfswörterbuch fïr Historiker, Eugen Haberkern und Joseph Friedrich Wallach, Francke Verlag, Tübingen, 19806. Arrha es un pago simbólico en un contrato; se usaba principalmente en el contrato matrimonial y en la transferencia de bienes que éste llevaba consigo; se lo identificaba con los términos (en 
el texto citado más arriba, queda también en claro la finalidad del escrito de Hugo; aquel soliloquium dilectionis, al que se refiere, nos centra ya desde el inicio, en el tema fundamental del diálogo; del mismo modo, como estas primeras líneas tienen un carácter dedicatorio a algunos personajes que sólo están nombrados por la inicial de su nombre, el tema propuesto tiene la finalidad de que el texto sirva para ese «verum amorem quaerere». De este modo, el amor es el tema central de la reflexión de Hugo, aunque para llegar a caracterizarlo como aspecto central del hombre interior, lleva a cabo una consideración más o menos pormenorizada de las distintas etapas por las que debe pasar el alma hasta encontrarlo. De allí que bajo el símbolo del arrha agrupe los diversos dones que el alma posee y que ha recibido, y que sea a partir de ellos cómo el alma llega a un conocimiento más profundo de sí misma para acrecentar el amor por el donante del arrha que no es sino Dios. Sin embargo, la dimensión propiamente sobrenatural aparece mediando el diálogo ya que en sus inicios el alma se encuentra, como veremos, en una situación que se podría calificar de natural tanto respecto del conocimiento como del amor.

Así, la cuestión de si el texto de Hugo de San Víctor es un soliloquio o un diálogo es una cuestión que no admite una estricta separación: el alter Augustinus, como fue llamado Hugo, apela a un método dialógico pero se trata de un diálogo cuyo ámbito es la interioridad del hombre como unidad. Se trata, pues, de un recurso estilístico aunque no se queda solamente en eso, sino que el texto es una auténtica reflexión sobre la vida del hombre interior, donde - como final- se da una coincidencia entre las expectativas del hombre respecto de su alma con los intereses de ésta respecto al unicum, es decir, al objeto central del amor que unifica la totalidad de las potencias, intereses y afectos del hombre y su alma.

\section{b) El análisis de "De arrha animae»}

El texto comienza con una breve introducción, antes de que se dé lugar el diálogo entre el hombre y el alma. En ella se refiere a varios personajes de la abadía de Hamersleben, donde Hugo había estado en sus primeros años de profesión religiosa. Ya hemos citado un texto de esta parte que me permito repetir: «Soliloquium dilectionis, quod de Arrha animae inscriptum est, nisi charitati vestrae, ut discatis ubi vos oporteat verum amorem quaerere, et quemadmodum debeatis corda vestra spiritualium studio meditationum ad superna gaudia excitare». ${ }^{33}$ Nos interesa señalar sobre todo la frase final del texto: «et quemadmodum debeatis corda vestra spritualium studio meditationum ad superna gaudia excitare». Aquí presenta la dimensión o el ámbito en el que se desarrollará el diálogo y que constituye, a la vez, el punto de partida de esa meditación que llega a gozar de las realidades máselevadas, a saber, el corazón. No se trata de una apelación a un mero sentimiento, sino al centro unificador que con la dedicación (studio) a la meditación se puede penetrar y abrir para ver su interior. Sin embargo, este ver y penetrar no tienen una finalidad erudita $o$ puramente psicologista, sino que se trata de una visión que ha de terminar en el acrecentamiento

este caso en alemán) Weinkauf (compra de vino), Bierkauf (compra de cerveza), o bien Imbiß (comida ligera), que se tomaba o comía en común por las partes que concertaban el contrato y con ello éste quedaba sellado. Por eso su significado simbólico, tal como aparece en el texto de Hugo, adquiere el significado de regalo, don, etc., y a la vez como lo común ya que pertenece al alma y al dador de esos bienes que el alma posee. Sobre el uso de arrha en sentido espiritual, cfr. S. Cirilo de Alejandría, Commentarium in Epistulam secundam ad Corinthios, 5, 5; PG 74, 942.

33 DAA, PL, 176, 951. 
del amor que, a su vez, lleva consigo el despertar del gozo por las cosas espirituales (superna gaudia). De este modo, resuenan las palabras de San Agustín: «quid autem amo, cum te amo?», ${ }^{34}$ es decir Hugo no presenta la cuestión del amor desde un punto de vista esteticista o formal, sino que tiene una clara intención de descubrir, al hilo de las palabras del obispo de Hipona, cuál es el objeto de ese amor y cuáles son las condiciones subjetivas para alcanzarlo. Hugo se propone dar cuenta de sí -y resuena aquí la sentencia agustiniana quaestio mihi factus sum-, y se propone exponerlo desde su intimidad para llegar al verdadero objeto del amor. ${ }^{35}$ Pero lo que busca Hugo es qué hay digno de ser amado y, si entre ello, figura algo que es el propio Dios, y además, algo que se vive en el amor de Dios que lo llene de felicidad y de plenitud con una visión capaz de colmar su ansia interior de amar.

\section{c) El diálogo}

Comienza hablando el hombre: «Loquar secreto animae meae, et amica confabulatione exigam ab ea quod scire cupio. Nemo alienus admittetur, sed aperta conscientia soli verba conferemus. Sic enim nec mihi timor erit occulta quaerere, nec illi pudor vera respondere». ${ }^{36}$ El diálogo que se entabla tiene un ámbito definido: loquar secreto animae meae, y al alma le exige poder llegar a conocer ea quo scire cupio. No se admitirá nada extraño o ajeno, sino que la conversación se realizará en el interior de la conciencia sin ningún temor ni pudor para desvelar lo oculto y poder así responder a las cuestiones que al hombre le interesan. Nos encontramos aquí con dos dimensiones que se mantendrán a lo largo del diálogo: un plano existencial y un plano objetual.

1. La cuestión existencial está definida por el hablar y el preguntar en primera persona: no se trata de una investigación sobre objetos, sino sobre la propia interioridad. Así, nos encontramos con un nivel epistemológico que se caracteriza por la introspección pero que, a la vez, no es una meditación solipisista: por el contrario —y esto se verá con más claridad un poco más adelante-, el hombre y el alma están en una relación dialogal, de mutua compañia que proporciona un refrendo veritativo al contenido del diálogo. Por eso se puede hablar aquí de una intimidad subjetiva, como opuesta pero a la vez complementaria, de una interioridad objetiva. La intimidad subjetiva no es una especie de subjetivismo (del sentimiento, o de la pura elucubración existencialmente vacía) sin relación a la verdad del yo. Es precisamente el yo el que se pone de manifiesto en toda su hondura y se despliega en su propia acción interior, guiado por un criterio de búsqueda de la verdad de sí mismo. Por ello, el yo no se objetiva, sino que se mantiene en un plano vivencial diverso al que presenta el alma. La relación del yo es con el alma y con sus acciones, con su vida, pero no se propone como el objeto, como lo que está frente a la mirada que hace de él una cosa (objeto). Su misión es investigar lo íntimo, su propia realidad existente, a través de una mirada dialógica que lo preserva de desdoblarse y ponerse frente a sí como un objeto. Por eso es quien lleva el hilo del diálogo y es el que pregunta al alma: desea conocer una serie de realidades que se dan en su propia existencia pero no como realidades objetuales sino como realidades vividas.

34 San Agustín, Confessiones, X, 6, 8.

35 S. Kierkegaard, La enfermedad mortal, Sarpe, Madrid 1984, p. 45: «En el caso de un ser humano, la comprensión es su captación de lo humano, pero creer es su relación con lo divino».

36 DAA, PL, 176, 951. 
2. El alma, en la textura del diálogo, es lo objetivado por el yo. Podemos hablar aquí de una interioridad objetiva, ya que el alma pertenece a la misma realidad del yo, pero Hugo la pone frente a él de modo de modo dialéctico: ${ }^{37} \mathrm{el}$ alma es interrogada, puesta a prueba, ilusionada, desencantada, exigida a dar respuestas sobre sí misma que parece no tener, etc. Es, en cierto sentido, lo accesible desde el yo en cuanto es lo objetivo de la existencia, y por ello no se sabe a sí misma sino que necesita de una subjetividad existencial que la ponga en presencia de sí y de lo que ella posee en su interior (arrha). Lo que el alma posee le ha sido donado, mientras que lo que el yo manifiesta es una vida espontánea que, sin embargo, necesita del alma para adquirir su verdadera plenitud. De este modo, los dos planos se integran.

El yo y el alma constituyen, pues, una unidad que se va poniendo de manifiesto en el crecimiento del conocimiento de sí que el alma va adquiriendo ante las interpelaciones del yo. Por eso el diálogo no separa dos realidades, sino que permite poner de manifiesto la íntima unidad del yo y el alma en una perspectiva teleológica: la finalidad de ambos es la misma; la separación es dialéctica pero, al mismo tiempo, se integra en la única subjetividad que se presenta en el texto de Hugo. La verdadera alteridad la encontraremos en el momento de confrontación del alma con los dones que posee y que le han sido dados y, más radicalmente, con el dador de tales dones. Pero en este punto, el yo y el alma se presentan como una unidad manifiesta puesto que el yo ha llevado al alma al punto que constituía su propio interés: el autoconocimiento es, a través del diálogo con el alma, un crecimiento espiritual, amoroso, de la integridad personal. Ahora bien, esta unidad se hace patente en la unidad de la conciencia: la aperta conscientia a la que se refiere Hugo no es ni propia del alma ni propia del hombre, sino que es una única realidad que pertenece al yo y, así, supera la escisión antes indicada entre el plano existencial y el plano objetual. Pero es precisamente en la dimensión de la conciencia donde aparecerá otra vez lo objetivo (occulta); sin embargo, aquí lo objetivo no es lo ajeno al yo, sino lo propio que es objeto mientras permanece oculto, mientras que cuando se descubre o se desvela, el yo ve que las cosas ocultas en la conciencia forman parte de su vitalidad interior. Lo objetivo en cuanto objetivo es, pues, lo desconocido: y he aquí una característica esencial del ámbito místico puesto que la relación de la interioridad con lo que ama y con lo que conoce en cuanto ama, es una relación vital que se consuma en una unidad en donde parte queda develado por la luz del conocimiento amoroso y parte queda en la sombra del misterio; el amor es, así, unitivo pues a través de él se manifiesta lo oculto, aparece a la luz de la conciencia lo que ésta todavía no sabe ni de sí misma ni sobre el término de su relación vital. De aquí que el plano de la pura objetividad está superado en el conocimiento místico por la presencia vital de la unidad amadoamante, o cognoscente-conocido. La superación de estas dicotomías muestran la dimensión unitiva (amorosa y cognoscitiva) entre el yo y Dios.

El discurso del hombre continúa con una interpelación al alma pero partiendo de una premisa que el alma no problematiza: «sé que tu vida es amor y que sin amor no puedes vivir». ${ }^{38} \mathrm{Lo}$ que el

37 Lo que anteriormente habíamos denominado recurso estilístico del diálogo, vemos ahora que no se trata de una pura ficción literaria, sino que estamos en presencia de un recurso epistemológico que permite mantener un plano existencialmente vivo (el yo) que se encuentra con otro plano de carácter objetivo pero generado en el mismo nivel existencial, es decir, no separado sino gnoseológicamente de la realidad de la primera persona.

38 DAA, PL, 176, 951: «Ego scio, quod vita tua dilectio est et scio quod sine dilectione esse non potes. Sed velim mihi sine verecundia confitearis, quid inter omnia diligendum elegeris? Dicam adhuc, ut manifestius intelligas quid te interrogem». Hugo de San Víctor utiliza a lo largo del texto los términos dilectio y amor de modo bastante riguroso, aunque 
hombre le pone delante al alma para que lo considere, son una serie de bienes y seres naturales --el mundo sensible-, para que trate de identificar entre esos objetos cuál es el objeto de su amor. Y lo que aparece a la consideración del alma se relaciona con el conocimiento natural y con la experiencia del mundo: «ecce tu novisti omnia, vidiste pene singula, experta plurima», ${ }^{39} \mathrm{y}$, de este modo el hombre hace una pregunta fundamental que es la que desencadena el resto del diálogo: «dic ergo obsecro mihi, quid de his omnibus unicum tibi feceris, quod singulariter amplecti, quo semper perfrui velis? $?^{40}$ La pregunta tiene dos temas centrales: el unicum y el semper. Lo que plantea Hugo de San Víctor no es una cuestión genérica sobre el objeto del amor y de los deseos, o bien un problema que atañe a la apetitividad sensible y espiritual por separado; sino que lo que está proponiendo es una búsqueda del verdadero amor que, ya desde el inicio, está objetivado como un unicum que se corresponde con una actitud subjetiva delimitada por el semper. De este modo hay una correspondencia: unicum-semper que le exige al alma un conocimiento de sí misma de modo tal que lo que siempre ame sea lo único que merezca ser amado, según la misma naturaleza del alma. La respuesta del alma es, en este primer momento, negativa: no ha encontrado todavía el objeto de su amor; pero la respuesta también pone de relieve que el alma ha mirado solamente a lo exterior, no ha ido hacia su propia interioridad. ${ }^{41}$ De aquí se plantea la cuestión del «yo soy», o mejor dicho, «qué es lo que yo soy». El alma sólo es feliz por el amor, pero al mismo tiempo tiene que conocerse a sí misma para ver las exigencias del amor que puede satisfacer sus ansias de felicidad.

Pero el alma no advierte su verdadero yo para determinarse al amor que pueda hacerla feliz. Aquí Hugo extiende las consideraciones sobre el mundo exterior como insatisfactorio en cuanto objeto del amor del alma, de modo que ésta le pregunta al hombre: «quomodo potest demonstrari, quod videri non potest? quod autem videri non potest, quomodo potest diligi?». ${ }^{42} \mathrm{El}$ alma tiene fija su mirada en el mundo exterior: no ha tenido todavía una percepción profunda de su yo, y por ello la respuesta por su propio yo es débil, o mejor dicho, presenta un yo débil que se manifiesta de modo explícito en la desorientación y en la desesperación; ${ }^{43}$ es por ello que le pide al hombre que le muestre el camino para salir de esa situación paradójica. Y es aquí cuando el hombre de modo explícito le muestra al alma el camino de la interioridad: si lo exterior no \a satisface, si no hay allí nada permanente digno de un amor para siempre y que, al mismo tiempo, satisfaga por completo al alma, pegunta el hombre: «cur teipsam potius non diligis, quae specie tua omnino visibilium decorem et pulchritudinem vincis? O si teipsam aspiceres! O si faciem tuam videres, agnosceres certe quanta.

no explicita la diferencia entre uno u otro; pero el significado de ambos términos está cercano a la tematización explícita que hace Tomás de Aquino, S. Th., I-II, q. 23, a. 3: «omnis dilectio vel caritas est amor, sed non e.converso. Addit enim dilectio supra amorem, electionem praecedentem, ut ipsum nomen sonat. Unde dilectio non est in concuspiscibile, sed in voluntate tantum, et est in sola rationali natura».

39 DAA, PL, 176, 952.

40 Ibid.

41 DAA, PL, 176, 953: «Sicut amare non possum quod nunquam vidi, sic de his omnibus quae videntur, nihil adhuc amare non potui, et tamen de his omnibus quid super omnia amandum sit nondum inveni. Multis enim jam experimentis didici fallacem esse, et fugacem amorem hujus saeculi, quem semper, vel cum perit id quod mihi elegeram perdere, vel cum aliud, quod magis placeat, supervenerit, cogor commutare; sic adhuc desideriis incerta fluctuo, dum nec sine amore esse possum, nec verum amorem invenio». En esta fluctuación del alma se ve de alguna manera lo que afirma San Agustín, Sermo 344, 1: «amores duo in hac vita secum in omni tentantione luctantur, amor saeculi et amor Dei».

42 DAA, ibid.

43 DAA, ibid. : «Certe si in rebus temporalibus, et quae videri possunt, verus et permanens amor non est, amari autem non potest, quod non potest videri, aeterna miseria semper viventem sequitur, si semper permanens amor non invenitur». 
reprehensione digna fueras, cum aliquid extra te amore tuo dignum existimabas!». ${ }^{44}$ De este modo, el hombre le propone el camino del desvelamiento del yo, la posibilidad de que responda a las preguntas antes formuladas sobre su propio yo; pero cabe hacer notar que la respuesta a esas preguntas tienen, por una parte, una dimensión interior no meramente objetiva: no se trata de ver una «cosa», sino el sí mismo; y, por otra parte, ese sí mismo no se encontrará en otro lugar que en el camino del verdadero amor: cur teipsam non diligis?, pregunta el hombre; allí está la clave para el descubrimiento del la interioridad, de su propia naturaleza, y en ella el reconocimiento del arrha, es decir de los dones que el alma ha recibido tanto por naturaleza, por constitución ontológica, cuanto aquello que ha recibido de modo amoroso por quien le ha dado su propio ser. El amor a sí misma, no representa, pues, una visión egocéntrica o meramente ensimismada, sino el modo como puede ver su propia realidad de modo completo: Hugo no se refiere aquí a un concepto de realidad meramente ontológica sino ontológico-existencial ya que se trata de reconocerse a sí mismo como vida y un tenerse-a-sí-mismo que es a la vez conciencia de ser poseído precisamente por lo que el sí mismo posee y se autoposee.

Sin embargo, el alma responde con una objeción al requerimiento del hombre de volverse hacia su interior: «Oculus cuncta videt, seipsum non videt». ${ }^{45}$ Es decir, todavía el alma no se ha percatado de la dimensión interior que tiene que explorar aunque reconoce que desde lo exterior y por indicios puede tener alguna noticia de lo que es (alienis indiciiis discunt homines facies suas). Pero añade una observación que es de sumo interés respecto al conocimiento amoroso: «amor numquam solitarius esse patitur» ${ }^{46}$ Es éste un punto central, ya que la objeción primera tiene aquí una vía de salida: se trata de una intuición fundamental respecto al conocimiento y al amor tomados conjuntamente ya que si, por una parte, el alma parece no poder verse, por otra, reconoce que el amor no se da en soledad de modo que el encerramiento que manifiesta a través del puro conocimiento, se abre a la alteridad en el amor. En realidad, como veremos más adelante, el alma reconocerá que también por el conocimiento se puede abrir a su interioridad, pero se trata de un conocimiento movido por el amor en una dimensión dialógica que tiene un doble resultado: el acrecentamiento del amor y el acrecentamiento del conocimiento, pero ambos están mutuamente necesitados. Lo que propone Hugo de San Víctor es una tesis que recorre toda la literatura mística: amor y conocimiento no son separables, uno lleva al otro y viceversa; es más, en el orden del puro conocimiento natural, es decir, fuera de una dimensión mística, la estructura cognoscitiva está también asentada en el amor que algunas veces puede llamarse deseo, o bien amor en sentido estricto, o incluso en su forma menos noble de curiositas $^{47}$ que lleva a la dispersión del ánimo, hay también allí una forma imperfecta de amor - tal vez puro deseo sin una sujeción a la razón recta一.

\section{DAA, ibid.}

45 DAA, ibid y PL, 176, 954: Y continúa el texto: «et eo lumine que reliqua cernimus, ipsam, in qua positum est lumen, faciem nostram non videmus. Alienis indiciis homines facies suas, et speciem vultus sui audiendo saepius quam videndo cognoscunt, nisi forte quoddam alterius generis speculum afferas, in quo faciem cordis mei cognoscam et diligam, quasi et illum non rectissime insipientem quisque diceret, qui ad pascendum amorem suum similitudinem vultus sui jugiter in speculo consideraret. Ego igitur quia faciem meam et speciem vultus mei qualis sit, contemplari nequeo, facilius in ea, quae foris admiranda videntur, affectum dilectionis meae extendo. Praesertim quia amor nunquam solitarius esse patitur, et in hoc ipso jam quodammodo amor esse, si desint in alterum parilitatis consortem vim dilectionis non diffundit».

46 DAA, ibid.

47 Actitud que el alma ha demostrado hasta este momento. 
El hombre inicia aquí un largo discurso de capital importancia para la argumentación posterior del diálogo. Lo introduce, a modo de premisa, con la siguiente afirmación: «non est solitarius, cum quo est Deus». ${ }^{48}$ Sin embargo, el hombre no sigue una línea de argumentación inmediatamente sobrenatural, sino que va poniendo las condiciones subjetivas para que el amor a Dios sea una realidad en el amante; es por ello que coloca en primer lugar un doble requisito, a saber, que el amor supremo se alcanza a partir del conocimiento de sí mismo y del abandono del amor de las cosas inferiores al hombre. ${ }^{49}$ La consideración de sí mismo tiene un momento de comparación con el resto de la realidad: se trata de ver la dignidad subjetiva y de eliminar así los encantamientos imaginativos que pueden presentar ciertas realidades como más bellas o más perfectas que el sujeto mismo. Estamos, pues, ante un momento veritativo que hace recordar la noción anselmiana de verdad como rectitudo. Si el amor no puede ser solitario, como el alma había dicho anteriormente, tampoco puede envilecerla con un encantamiento falso basado en realidades que no están a la altura de su dignidad. ${ }^{50}$ Pero el amor verdadero tiene carácter de elección, es decir, no se trata de un puro impulso hacia los objetos exteriores y ni siquiera hacia sí mismo: «quaeris unicum, quaere et unice electum». ${ }^{51}$ Nos encontramos, pues, con una dimensión propia del amor como acto de la voluntad que ama lo que elige, o elige lo que ama; de todos modos, como ya ha aparecido, no está ausente la componente cognoscitiva: al contrario, la elección se realiza a través de un juicio que tiene en cuenta lo que puede ser objeto de verdadero amor o de amor falso o sobre cosas aparentes. El amor, dice Hugo, es fuego pero no hay que confundirlo con el humo o los olores que de él derivan: ${ }^{52}$ el engaño siempre acecha las puertas del verdadero conocimiento de sí mismo y del verdadero amor. Y en este sentido la verdad se presenta ardua, activa, al modo de una lucha que el sí mismo debe combatir contra sí para mantenerse fuera del engaño y poder descubrir la verdadera realidad. Pero ¿cómo evitar la apariencia engañosa?: «Non est tibi invisibilis facies tua. Oculus tuus nihil bene videt, si seipsum non videat», ${ }^{53}$ es decir, la introspección reflexiva hace que el ojo se vea a sí mismo; la propia realidad subjetiva es perceptible al sujeto mismo; no hace falta mirar hacia fuera o bien que al sujeto le digan lo que es, sino que él mismo debe verse para ver.

Por eso afirma el hombre: «tuam igitur anima pulchritudinem attende et intelliges qualem debeas pulchritudinem diligere», ${ }^{54}$ pues el alma está llamada a convertirse en la figura del amado, es decir, el amor y el conocimiento del amado lleva al alma a alcanzar una similitudo con él. Pero el alma tiene que ver entonces al amado para tratar de lograr esa similitud. La dificultad que pre-

48 DAA, ibid. El discurso del hombre se encuadra perfectamente en estas palabras de S. Pedro Crisólogo, Sermo 147, PL 52, 594: «Amor, nisi ad desiderata pervaserit, necat amantem; et ideo, vadit quo ducitur, non quo debeat. Amor facit desiderium, gliscit ardore, ardore ad inconcessa pertendit». Lo que está planteado aquí es la dimensión totalizante del amor que debe llegar a todo el ser de la persona de otro modo se vuelve en contra de ella: necat amantem. El discurso que propone Hugo de San Víctor va en esta línea, como veremos, y de este momento en más, el hombre entabla una «lucha» con el alma para que ésta siga un camino de purificación que va de la mano del conocimiento interior.

49 DAA, PL, 176, 954: «Primum igitur necesse est, ut quisque semetipsum consideret, et cum cognoverit dignitatem suam (ne injuriam faciat amori suo) abjectiora se non amet».

50 DAA, ibid.: «Non vis habere anima amorem solitarium, noli tamen habere prostitutum».

51 DAA, ibid.

52 DAA, ibid.: «Scis quod amor ignis est, et ignis quidem fomentum quaerit ut ardeat. Sed cave ne id injicias, quod fumum potius aut fetorem ministrat».

53 DAA, ibid.

54 DAA, ibid. 
senta Hugo es que el amado no es directamente visible por el alma; sin embargo afirma: «sponsum habes, sed nescis», ${ }^{55}$ por lo que la tarea del alma, es decir, su propia visión tiene que llevar al conocimiento del esposo. El alma, pues, debe salir de la ignorancia de sí misma atendiendo a su propia belleza y a su propio ser con el fin de acceder al amor y al conocimiento del amado que, hasta que el alma no salga de su ceguera, permanecerá oculto. De allí que afirma el hombre: «Si adhuc scire non potes qualis ille sit, qui te diligit, considera saltem arrham, quam dedit», es decir, el alma es amada pero no sabe de ese amor al que, sin embargo, puede acceder a través del conocimiento de los dones que ha recibido y lleva consigo. Pero esos dones tampoco se presentarán de un modo definitivo o, al menos con toda su claridad derivada de una presencia completa: «in signis est arrha ejus» ${ }^{56}$ Pero el amor a las cosas creadas, de las cuales el alma tiene conocimiento, deben ser amadas según una condición: «Certe si haec diligis, ut subjecta dilige, ut famulantia dilige, ut dona dilige, ut arrham sponsi, ut munera amici, ut beneficia Domini», ${ }^{57}$ es decir, hay un orden en el amor que nace como de tres momentos del conocimiento: por una parte, el conocimiento de la creación; en segundo lugar, como conocimiento que el alma tiene de sí misma y de los dones que ha recibido; y, en tercer lugar, el conocimiento del dador de los dones que aquí implica tanto la creación, lo exterior al alma, cuanto los dones interiores al alma. Estos son, pues, los signos en los cuales el alma debe sustentar su conocimiento y su amor.

El alma entonces manifiesta un gran entusiasmo porque le ha sido revelado no sólo el objeto de su amor, sino también el camino interior por el cual puede llegar al conocimiento del dador de ese amor y de los bienes que el alma posee en sí misma y fuera de $s^{\prime} .^{58}$ Sin embargo, el alma presenta una queja: todos esos bienes parecen ser comunes a todos los hombres, pero ella quiere amar de modo único y ser amada del mismo modo ${ }^{59}$ En este momento el alma toma conciencia de su unicidad: la objeción que presenta implica que se está considerando a sí misma como algo irrepetible de modo que ha accedido a un conocimiento propio mayor; en efecto, el amor común a varios no la satisface no porque no sea verdadero amor sino porque toma conciencia de su individualidad y, con ello, de la respuesta también única que ese amor merece, de modo que es el sí mismo el que aparece con una exigencia de relación única entre amante y amado. La respuesta del hombre no tarda en llegar: «singulariter data sunt, quae tibi soli sunt data». ${ }^{60}$ De todos modos, el hombre le presenta al alma un panorama amplio. Es verdad que el donante del amor ama a todos los hombres, pero esto constituye para el alma también un bien: distingue el hombre la donación creatural en varios niveles. La creación natural, para la cual Dios tiene un determinado amor, en la que distingue las cria-

55 DAA, ibid.

56 DAA, PL 176, 955. Y continúa el texto: «Dicam igitur tibi, ut scias quid dedit sponsus tuus. Respice universum mundum istum, et considera si aliquid in eo sit, quod tibi non serviat. Omnis natura ad hunc finem cursum suum dirigit, ut obsequiis tuis famuletur, et utilitati deserviat, tuisque oblectamentis pariter et necessitatibus secundum affluentiam indeficientem occurrat. Hoc coelum, hoc terra, hoc aer, hoc maria, cum iis, quae in eis sunt, universis, explere non cessant; in hoc circuitus temporum annuis innovationibus, et redivivis partibus antiqua innovans, dilapsa reformans, consumpta restaurans, pastu perpetuo subministrat. Quis ergo putas hoc instituit? quis istud naturae praecepit ut sic uno consensu tibi serviat? beneficium accipis, et auctorem ejus non agnoscis».

57 DAA, ibid.

58 Cfr. DAA, PL 176, 956.

59 DAA, ibid.: «ecce igitur ego unice electum et unice dilectum diligo». DAA, PL 176, 957: «ego autem hoc quaerebar, quod unice diligens, unice dilecta non sum, quia pignus amoris mei aliis aeque video esse concessum».

60 DAA, PL 176, 957. 
turas carente de vida de las que tienen vida y que, por tanto, son amadas de modo diverso. El hombre, creado a imagen y semejanza de Dios, goza de un amor especial en dos sentidos: primero en cuanto que su estructura ontológica lo asemeja a Dios, y en segundo lugar, la semejanza no solamente es entitativa sino también operativa en el sentido de que el alma debe buscar la similitudo por vía de conocimiento y de amor. Pero se debe tener en cuenta lo dicho anteriormente: la sociedad de los hombres, amados por Dios, es en sí misma un bien de modo que compartir el amor no implica un mengua del amor al individuo, sino que cada uno es amado en sí y por sí, pero al mismo tiempo, al ser todos amados conforman una sociedad cuyo vínculo estrecha las relaciones entre los hombres. De este modo el alma llega al conocimiento no solamente de su individualidad, sino de la comunidad de amor y de la semejanza: se abre, pues, aquí el ámbito de la intersubjetividad basada no solamente en una comunidad de naturaleza sino en la comunidad del amor recibido, de manera que sin anular la unicidad del individuo, cada uno de ellos entra en contacto amoroso con sus semejantes y así se ve, desde otra perspectiva, que esa comunidad es parte del arrha que el alma posee; ${ }^{; 1}$ así, el amor común a todos los hombres lleva a una sociedad de amantes, a una unidad intersubjetiva: «omnes autem in uno se quasi unum diligant, ut unius dilectione unum fiant». ${ }^{62}$

De este modo Hugo de San Víctor distingue tres órdenes de amor: uno común a toda la creación, otro especial con el que Dios ama a todos los hombres y les comunica parte de sus bienes, y en tercer lugar, un amor singular que corresponde al individuo; ${ }^{63}$ ahora bien, el alma es amada en estos tres órdenes ya que no son excluyentes entre sí ${ }^{64}$ Pero el discurso no termina aquí ya que el hombre afirma: «Tibi loquor, anima mea, tu nosti quid acceperis, et necesse habes adhuc melius nosse». ${ }^{65}$ En primer lugar, se encuentra el don de la existencia,${ }^{66}$ que el alma lo recibe gratuitamente ${ }^{67}$ además el alma ha recibido la belleza junto con el ser; ${ }^{68}$ y en tercer lugar, lo que es considerado de más importancia respecto a la vida del alma, ya puesta en el ser y con su belleza propia, que

61 DAA, PL 176, 958: «Quid autem de societate bonorum dicam? Nam hoc solum nunc restat, ut consideres utrumne idcirco de singulari amore sponsi tui gloriari non possis, quod ab eo non sine societate bonorum diligeris. (...)Dixi enim etiam societatem hominum dono tibi Creatoris esse concessam, ut inde solamen vivendi capias, ne quadam solitaria et inerti vita destituta contabescas. (...) Licet igitur beatum esset, isto amore te vel solam perfrui, multo tamen beatius est in ipso cum multorum bonorum congratulatione delectari, quia cum in eos etiam, qui comparticipant, affectus dilectionis expanditur, charitatis gaudium et suavitatis ampliatur. Spiritualis namque amor tunc melius cuique fit singularis, quando omnibus est communis. Nec participatione plurium minuitur, cujus fructus unus et idem totus in singulis reperitur».

62 DAA, PL 176, 959. No nos detenemos en la consideración eciesiológica de este tema que sin embargo sería de sumo interés ya que en estas páginas nuestra finalidad no es teológica, aunque no se puedan evitar ciertas referencias teológicas por la naturaleza misma del texto.

63 Ibid.: «Communia quidem sunt ea, quae in usum universorum veniunt, sicut est lux solis, spiramen aeris. Specialia vero, ut ea, quae non omnibus, sed quasi quidam societati concessa sunt, sicut est fides, sapientia, disciplina. Singularia autem ut ea, quae unicuique propria impertita sunt (...)».

64 Ibid.: «In omnibus iis te dilexit, quae vel cummuniter tecum omnibus, vel specialiter quibusdam, vel singulariter tibi soli tribuit».

65 Ibid.

66 Ibid.: «Primum cogita anima mea, quod aliquando non fueris, et ut esse inciperes, hoc ejus dono acceperis».

67 Aunque aquí sigue el diálogo entre el hombre y el alma, los bienes que recibe el alma son en realidad algo que atañe al individuo, al hombre completo. Es decir, el recurso del diálogo no puede hacer olvidar que todo el texto de Hugo es una reflexión sobre la totalidad del sí mismo.

68 Ibid.: «Nunc autem amplius dedit, quia dedit non solum esse, sed pulchrum esse, formosum esse, quod quantum superat nihil per existentiam, tantum antecedit aliquid per formam, in quo multum placet id quod est, et amplius id quod tale est». 
es la similitud con Dios ${ }^{69}$ que se realiza por el amor o por la correspondencia en el amor ya que por sí misma el alma nada posee - «nihil a te habuisti»_- ${ }^{70}$ y así «magno debito obligata es anima mea», ${ }^{71}$ y ese deber de gratitud se realiza mediante el amor con que el alma debe amar a Dios: «nam quod per dilectionem datum est, nec melius nec decentius quam per dilectionem rependi potest. Accepisti autem hoc totum per dilectionem. Poterat enim Deus etiam aliis creaturis suis dedisse vitam, sed amplius in hoc dono dilexit te. Nec ideo plus dilexit te, quoniam plus diligendum invenit in te, sed quia gratuito plus dilexit te, talem fecit te ut jam nunc merito plus diligat te». ${ }^{72}$

En este lugar Hugo sigue enumerando los dones que el alma ha recibido $;^{73}$ sin embargo, en el camino místico señalado por Hugo, también se encuentra la realidad de la culpa. Es decir, el alma no siempre fue consecuente con lo que recibió de Dios y, como se planteaba al inicio del diálogo, el alma estaba volcada hacia lo exterior sin reconocer en ello la mano de Dios, del mismo modo que la falta de conocimiento de sí misma tampoco le permitía ver lo que en sí misma poseía. A causa de estas dos dificultades, que revelan superficialidad en el alma, aparece la culpa como amor indebido que deteriora la naturaleza del alma: «Corrupisti integritatem tuam, foedasti pulchritudinem tuam, dispersisti ornatum tuum. Tam vilis, et tam turpis, et tam immunda facta es, quasi talis sponsi amplexibus amplius digna non esses. Oblita es ergo sponsi tui, et pro tantis beneficiis condignas gratias non egisti. Meretrix facta es, et prae nimiis fornicationibus tuis laxata sunt ubera tua. Rugosa effecta est frons tua, genae marcidae, languentes et stupentes oculi, labia pallore obducta, exsiccata cutis, virtus infracta, ipsis quoque amatoribus tuis odiosa». ${ }^{74}$ Las palabras del hombre son duras, pero tienen también la finalidad de un mayor conocimiento que el alma pueda alcanzar: delante de la realidad del amor está también la realidad de la culpa que impide ese amor. El alma manifiesta estar confundida: cuando consideraba los dones que había recibido y la realidad del amor mutuo se sentía feliz, pero en este momento debe reconocer su culpa. ${ }^{75}$ Es éste un paso necesario de la vida mística, es decir, la purificación que sólo llega ante el reconocimiento de la falta de similitud del alma con Dios, a causa de las propias acciones del alma; por ello replica el hombre: «non ad confusionem tui, sed ad eruditionem dicta sunt». ${ }^{76} \mathrm{Se}$ ve con claridad también aquí que el conocimiento es necesario para amar tanto como acto positivo, como por el aspecto negativo de la culpa: es necesario librarse de ella y, para esto, es necesaria reconocerla de modo tal que el conocimiento del alma tal cual es, sea motivo de un mayor acrecentamiento del amor que es, a la vez, un mayor acrecentamiento del conocimien-

69 DAA, PL 176, 960-961: «Adhuc aliquid plus dedit, et magis nos ad similitudinem suam traxit; voluit ad se trahere per similitudinem quos ad se trahebat per dilectionem».

70 DAA, PL $176,961$.

71 Ibid.

72 Ibid.

73 Ibid.: «Post esse, et post pulchrum esse, post vivere, datum est et sentire, datum est et discernere. (...)Sensibus foris decoravit, intus sapientia illustravit. Sensus dans quasi exteriorem, sapientiam quasi interiorem habitum. Sensus quasi quasdam gemmas fulgentes appendens exterius, sapientiam quasi naturali pulchritudine faciem vultus tui decorans intus. Ecce ornatus tuus, omnium gemmarum vincit pulchritudinem, ecce facies tua omnium formarum superat decorem. Talem omnino esse decebat, quae ad coelestis regis thalamum introducenda fuerat».

74 DAA, PL 176, 961-962.

75 S. Kierkegaard, Der Begriff der Angst, en Gesamnelte Werke, vol. 5, Jena 1905, p. 107: «La culpa es una representación más concreta, que estando con la libertad en la relación de la posibilidad resulta cada vez más posible. (...) Pero quien se convierte en culpable se hace a la vez culpable por haber dado ocasión a la culpa; porque la culpa nunca tiene un origen externo, y quien cae en la tentación es culpable también de la tentación».

76 DAA, PL 176, 962. 
to. Por eso, el hombre le hace considerar el perdón de Dios respecto a su culpa lo cual incluye una nueva dimensión del propio conocimiento anímico, es decir, no solamente posee bienes naturales, dones que se le han dado al alma juntamente con su propia existencia, sino que a través de la purificación de la culpa, aparece una nueva forma de amor. Dios rescata al alma: «cogita quantum diligat te, qui tanta facere dignatus est propter te». ${ }^{77}$ Así el alma recobra sl' felicidad pero a un nivel superior que nace del conocimiento de lo que Dios ha hecho por ella para rescatarla de su culpa. ${ }^{78}$ Por su parte, la culpa abre un camino intencional y personal. No es, en efecto, la rectitud del amor, pero la culpa revela que la intencionalidad del conocimiento tiene un correlato en la intencionalidad del amor, aunque por su naturaleza culposa no sea un crecimiento personal y tampoco propicie una unión personal con Dios, sino, por el contrario, un alejamiento. ${ }^{79}$ De todos modos, la negatividad de este hecho habla de las diversas dimensiones de la interioridad que no está determinada ad unum, sino que por la libertad que goza puede no reconocerse en su verdadera dimensión y, por ello, puede alejarse no solamente del amor divino, sino más primariamente de su propia naturaleza en el sentido de que ésta, en cuanto perfectible, puede no obstante concentrarse en algo que no le pertenece, aunque en apariencia establezca una relación de pertenencia con aquello que la aleja del verdadero conocimiento propio y del verdadero amor. El reconocimiento, pues, del error, de la culpa, lleva al conocimiento de la verdad: fenomenológicamente significa un cambio de dirección intencional, aunque parece que la intencionalidad se manifiesta como independiente de la verdad. Por ello, el sí mismo debe recurrir a una dimensión dialógica para reconocer el error y, al mismo tiempo, en esa dimensión pueda recuperar su verdadero conocimiento y amor.

De aquí que Hugo de San Víctor propone una vía expiatoria, de purificación como momento necesario para la rectitud del conocimiento y del amor, ${ }^{80}$ por ello el alma pide: «quaeso igitur ut non pigriteris per singula mihi ediscere, quae sint illa remedia quibus faciem meam debeam ad hunc decorem reformare, quia vehementer illi placere cupio, cujus charitatem erga me tam benignam et amorem tam jucundum agnosco». ${ }^{81} \mathrm{El}$ alma manifiesta que todavía necesita aprender para reformarse ya que desea vivamente complacer al dador de los bienes que posee, al que le ha perdonado la culpa y cuyo amor es ya, para el alma, algo no tanto conseguido cuanto conocido. El alma, en efecto, conoce cuál es el objeto de su amor, pero debe seguir un camino amoroso para que ese conocimiento se transforme verdaderamente en vida de sí misma. Lo que Hugo propone como medios de conversión para el alma son los sacramentos, las obras de caridad y el ejercicio de las virtudes, ${ }^{82}$ pero al mismo tiempo le habla al alma de algo que ella desde sí misma puede obrar: «habes lacrymas, quibus iterum te abluas». ${ }^{83}$ Es decir, hace un llamado a su intimidad para que desde ella surjan los actos

77 Ibid.

78 Ibid.: «O felix culpa mea, ad quam diluendam dum ille charitate trahitur, ipsa quoque ejus charitas mihi desideranti, et totis eam praecordiis concupiscenti aperitur».

79 S. Kierkegaard, La enfermedad mortal, cit., p. 45: «cristianamente entendido, el pecado radica, pues, en la voluntad, no en el conocimiento; y esta corrupción de la voluntad va más allá de la conciencia del individuo particular». En efecto, el pecado es ante Dios precisamente en lo que tiene de positivo.

80 DAA, PL 176, 964: «Prius ergo stude formam tuam excolere, faciem ornare, habitum componere, maculas tergere, munditiam reparare, mores corrigere, disciplinam servare, et omnibus tandem in melius commutatis digno sponso dignam sponsam reddere».

81 DAA, PL 176, 965.

82 Cfr. DAA, PL 176, 966.

83 . Ibid. 
necesarios para la purificación, actos que por ser personales causan un movimiento interior de purificación y de despojo de la culpa, que ponen al alma otra vez en condiciones de vivir según la similitudo. Se trata, pues, de la apertura completa de la conciencia, que se plantea al comienzo del diálogo, ante quien la perdona y le otorga su amor, es decir, el alma puede reestablecer a través de lo recibido una plena comunión y una plena intersubjetividad con quien la ama. ${ }^{84}$ Por eso se dirige al alma: «ecce habes, anima mea, arrham tuam, et in arrha tua cognoscis sponsum tuum». ${ }^{85}$

De este modo declara el alma: «ex quo constat quod licet facies ejus adhuc a nobis non possit videri, nunquam tamen possit praesentia ejus evitari», ${ }^{86}$ a partir de lo cual Hugo pone en boca del alma una serie de declaraciones que se pueden resumir en las diversas preguntas que el alma se hace a sí misma y que en esencia formulan el interrogante de cómo Dios puede amar al alma culpable y pecadora. Así se explica la reacción del alma ante sus culpas: el rechazo que manifiesta, a la vez, desamor y amor; es decir, odio hacia el pecado y amor al dador de los bienes que posee. ${ }^{87} \mathrm{De}$ este modo, aparece la claridad en la conciencia respecto a sí misma y respecto a Dios: «habeo aliud exemplar cui conformari cupio, et ad aliud jugiter respicio, ac quantum possum magis semper ac magis exinde similitudinem traho. Et quo hoc etiam didici, quod vos exterminare debeo, et qualiter hoc faciam jam agnoscos. ${ }^{88}$ Se produce, pues, un movimiento de auténtica conversio que, sin embargo, no pone al alma fuera del alcance de la tentatio, ${ }^{89}$ de aquí ese: «vos exterminare debeo, et qualiter hoc faciam jam agnosco» que se fundamenta en el conformari cupio respecto al ejemplar que le ha sido presentado de modo tal que se haga realidad en el alma la similitud con Dios que ya conoce, y respecto de la cual conoce el modo de hacerse con ella. De todos modos, agrega el hombre que el amor se digna a amar lo que es imperfecto, ${ }^{90} \mathrm{y}$ así el alma es amada en su realidad: con sus deseos de amar, pero también con los peligros de los que no se puede librar que aparecen en la tentatio. Por ello añade el hombre que el amor que el alma posee como arrha no desaparece a pesar de las limitaciones que el alma lleva consigo. ${ }^{91}$ Por eso el alma declara que está convencida, a par-

84 DAA, PL 176, 967-968: «Tu dedisti mihi, Domine, ut te agnoscam, et prae caeteris multis de tuis secretis revelata intelligam. Alios coaetaneos meos in tenebris ignorantiae dereliquisti, et mihi prae illis lumen sapientiae tuae infudisti. Tu dedisti mihi verius cognoscere te, purius diligere te, sincerius credere in te, ardentius sequi te. Tu dedisti mihi sensum capacem, intellectum facilem, memoriam tenacem, linguam disertam, sermonem gratum, doctrinam suasibilem, efficaciam in opere, gratiam in conversatione, provectum in studiis, effectum in coeptis, solamen in adversis, cautelam in prosperis, et quocunque vertebam me, ubique gratia tua et misericordia praecessit me. Et fecisti promo omnia saepe cum mihi consumptus videbar, subito liberasti me; quando errabam, reduxisti me; quando ignorabam, docuisti me; quando peccabam, corripuisti me, quando tristabar consolatus es me, quando desperabam confortasti me, quando cecidi erexisti me; quando steti, tenuisti me, quando ivi duxisti me; quando veni, suscepisti me. Haec omnia mihi fecisti, Domine Deus meus, et alia multa de quibus mihi dulce erit semper cogitare, semper loqui, semper gratias agere, ut te laudem et amem pro omnibus beneficiis tuis, Domine Deus meus».

85 Ibid. Un texto de San Agustín profundiza más esta idea: «ecce ubi sum: flete mecum, et pro me flete, qui aliquid boni vobiscum intus agitis unde facta procedunt», Confessiones, $\mathrm{X}, 33,50$.

86 DAA, PL 176, 968.

87 DAA, PL 176, 969: «recedite ergo, in vanum amplius mihi adhaeretis, quia, etiam mecum manentes, meae non estis. Alienas vos a sorte mea judico, et vobiscum deinceps nullam communionem habere volo».

88 Ibid.

89 San Agustín, Sermo 344, 1: «amores duo in hac vita secum in omni tentatione luctantur, amor saeculi, et amor Dei». Y en otro texto más explícito sobre la tentatio: «contendunt nobiscum quotidie tentationes, contendunt quotidie delectationes: etsi non consentiamus, tamen molestiam patimur», Enarrationes in Psalmos, 148, 5.

90 Ibid.: «nam et hoc quoque ad laudem dilectionis ejus pertinet, quod imperfectam diligere dignatur».

91 DAA, PL 176, 969-970: «Et quamvis quaedam adhuc in te videat, quae sibi non placent; diligit tamen hoc ipsum, quod tu quoque ea in temetipsa jam odisse coepisti quae illi displicent». 
tir del propio conocimiento y a partir del conocimiento del amor de Dios puede renovarse y vivir de un modo completamente diverso: «subito enim innovor et tota immutor, et bene mihi esse incipit ultra quam dicere sufficiam» ${ }^{92}$ de modo tal que dará batalla para no retroceder en lo que ha conquistado, que lo desea ardientemente como su propio fin, que todo otro deseo le estará supeditado y que no buscará ni apetecerá otra cosa que el amor que ha recibido «semper sic volens». ${ }^{93}$

De allí la última recomendación del hombre: «ya hemos dicho muchas cosas, y te pido alma mía, que conozcas a uno solo, a uno ama, sigue sólo a uno, hazte con uno solo, posee sólo a uno», ${ }^{94}$ a lo que el alma responde: «hoc opto, hoc desidero, hoc totis praecordiis concupisco». ${ }^{95}$

\section{SOBRE LA MÍSTICA Y ALGUNOS ACTOS ANÍMICOS}

\section{a) Los puntos de partida}

La consideración de los textos de Hugo de San Víctor nos ponen en condiciones de llevar nuestra reflexión un poco más adelante ya que en ellos hay una gran riqueza espiritual a la que se puede - 0 se debe - acceder no tanto de un modo racionalístico sino más bien de un modo vivencial o, si se quiere, fenomenológico. Esto se debe fundamentalmente a que el De arrha animae no es un texto teórico, o mejor una teoría sobre la vida mística, sino por el contrario un texto místico donde los datos aparecen de un modo directo, vivido. El modo cómo Hugo presenta sus reflexiones, como hemos visto, es una manera que habla claramente de esta dimensión vivida: el diálogo no es otra cosa que una reflexión ${ }^{96}$ del hombre interior que busca su identidad. Ahora bien, esta identidad es esencialmente relacional: reflexión, conocimiento, amor son actos intencionales que en el texto están presentados de modo implicado en todas las direcciones posibles. De todos modos, es el amor el que mueve a los demás de un modo primario ya que la reflexión que conduce al conocimiento del sí mismo no tiene otra finalidad que la actualización del amor, que a su vez, está caracterizado como mutua donación; en efecto, el alma descubre el objeto del amor verdadero, recorriendo un camino cognoscitivo-afectivo, como una realidad primera que le ha sido dada y a la cual ella tiene que responder con su propio amor, es decir, con su propia donación.

92 Ibid. Y continúa el texto: «Exhilaratur conscientia, in oblivionem venit omnis praeteritorum dolorum miseria, exsultat animus, clarescit intellectus, cor illuminatur, desideria jucundantur, jamque alibi (nescio ubi) me esse video, et quasi quiddam amplexibus amoris intus teneo, et nescio quid illud sit, et tamen illud semper retinere, et nunquam perdere toto adnisu laboro».

93 Ibid.

94 DAA, PL 176, 970: «Vere ille est dilectus tuus qui visitat te, sed venit invisibilis, venit occultus, venit incomprehensibilis. Venit ut tangat te, non ut videatur a te; venit ut admoneat te, non ut comprehendatur a te; venit non ut totum infundat se, sed ut gustandum praebeat se; non ut impleat desiderium, sed ut trahat affectum; primitias quasdam porrigit suae dilectionis, non plenitudinem exhibet perfectae satietatis. Et hoc est quod maxime ad arrham desponsationis tuae pertinet, quod ille, qui in futuro se tibi videndum, et perpetuo possidendum dabit, nunc aliquando (utquam dulcis sit agnoscas) se tibi ad gustandum praebet. Simul etiam interim de absentia ejus consoleris, quando ejus visitatione ne deficias incessanter reficeris. Quaeso, anima mea, multa jam diximus, post haec omnia unum agnosce, unum dilige, unum sequere, unum apprehende, unum possides. Hugo le plantea aquí al alma la forma en que el Esposo se presenta: como invisible, oculto, etc., es decir, para el alma la presencia del amado no es objetiva sino vital y su capacidad de ver depende estrictamente de la unión con el amado.

95 Ibid.

96 Volveremos sobre el tipo de reflexión que aparece en el texto. 
De este modo, el estudio de un texto místic $0^{97}$. puede asumirse como una consideración fenomenológica de la conciencia religiosa y, así, de alguna manera se renuncia a una filosofía constructiva de la religión. ${ }^{98}$ Lo que se asume, aunque no de modo único o unilateral, es una perspectiva histórica que, dado el carácter del texto y las claves intencionales que posee, se amplía a una investigación sobre los fenómenos genuinamente clarificados y percibidos como fenómenos originarios de la conciencia. De todos modos, para no perder la perspectiva auténtica del texto de Hugo, volvemos a lo anteriormente dicho, es decir, lo que en el texto se manifiestan son relaciones intencionales, de modo que la conciencià no es conciencia pura, yo puro o autónomo, sino una conciencia que se constituye en sus percepciones relacionales.

Desde un punto de vista histórico, hay que tener en cuenta las fuentes del pensamiento del Victoriense; sin embargo, la consideración de su inserción en una tradición de carácter fundamentalmente agustiniano y neoplatónico, no nos debe hacer perder de vista lo dicho en los párrafos anteriores, es decir, que aquí estamos tratando con un tipo de vida, con unos actos propios y unas consecuencias determinadas no por el hecho histórico, sino precisamente por el tipo de vida que Hugo presenta en el texto. Nos encontramos, pues, con un tipo de vivencia que se denomina mística, que tiene una propia autenticidad con independencia de los lazos históricos en la que tal vivencia se verifica. Esto no significa, sin embargo, que la historia no pueda ser asumida como una vivencia, o mejor dicho, que la tradición heredada no pueda convertirse en vida. Sino que precisamente en la medida en que se transforma en vida, la historia queda relegada a un plano ilustrativo. ${ }^{99}$ Por ello, el orden que sigue Hugo tiene una determinada racionalidad, unas secuencias lógicas, que parten de los presupuestos teóricos del autor sobre lo que es la vida mística. De todos modos, lo que se esfuerza en presentar no es la teoría de la mística, sino los hechos de conciencia que están en los supuestos no de una teoría sino de un tipo de vida. De alguna manera, tales hechos son proto-científicos, no están mediados por una construcción teórica, sino que en todo caso son ellos los que nos dan, en su carácter elementar, el material para una reflexión teórica susceptible de asumir categorías que no están expresamente manifestadas en los hechos en cuanto hechos. Éstos son, como queda claro en el texto de Hugo, originarios y su sistematización es obra de otro tipo de reflexión que puede ser iluminadora, pero que por ser reflexión se coloca en un nivel diverso a los hechos mismos.

La relación propuesta por Hugo entre reflexión, conocimiento y amor, define los rasgos más hondos de la interioridad: su discurso es teleológico, es decir, parte de instancias vivenciales que son las más exteriores de la vida subjetiva —relación del sí mismo con la realidad material, p.e.-, hasta llegar al descubrimiento de la verdadera interioridad que es también comprehensiva de aquellas instancias exteriores. El amor va marcando el camino de modo que la trilogía reflexión, conocimiento, amor, va tomando modulaciones diversas en orden a la constitución del sí mismo. En primer lugar, nos encontramos con una presencia, una alteridad constante al sí mismo; esta presencia es caracterizada como objeto de amor al cual el hombre tiene que adecuarse según la naturaleza del amor mismo y según la realidad de su propia subjetividad. Así aquella trilogía se trastoca en descu-

97 Me refiero fundamentalmente al texto que hemos considerado, aunque no se excluyen del todo consideraciones de carácter más general.

$98 \quad 0$, si se quiere, a un tratado sistemático de espiritualidad o de mística.

99 Lo cual no significa que se pueda prescindir de la historia: si se prescindiera nos colocaríamos en la perspectiva de una reflexión sin supuestos, lo cual es imposible. 
brimiento, purificación, amor que suponen una variedad numerosa de actos: conocimiento espiritual, arrepentimiento, negación de lo caduco de la propia interioridad, deseo, gozo, posesión, etc. Lo que pretende Hugo es despertar y alentar la vida religiosa y ésta, de algún modo, no tiene origen sino en sí misma: es decir, no se trata de una autoproducción, sino de una vida relacional propia. Lo genuinamente religioso no lo puede comprender sino el hombre religioso. Y no es esto una petición de principio, sino que tal como Hugo lo plantea, lo religioso nace de un don, del arrha, ante el cual el hombre responde y se configura con él, de modo que el motivo radical de la religiosidad está, por un lado, en la capacidad receptiva del hombre y, por otro, en lo que efectivamente recibe. Pero esto plantea una cuestión de niveles, es decir, el conocimiento, el amor, la interioridad definidas religiosamente pertenecen a un estrato anímico y objetual que no es del hombre puramente natural. Lo que se recibe es aquí lo definitorio, al tiempo que también lo es la modalidad subjetiva del recibir, que no es puramente pasivo sino generativo de un nivel relacional ante una realidad que al mismo tiempo que se manifiesta se oculta y que genera no sólo relaciones cognoscitivas sino también amoroso-afectivas. Lo que describe Hugo es una revelación, el descubrimiento de un misterio del que es partícipe el alma. Por eso ésta no responde teorizando, sino de un modo vivencial, originario, y así los actos de conciencia son directos, genuinos, relativos de modo directo a una realidad amorosa. ${ }^{100}$

\section{b) La percepción}

«Ego scio, quod vita tua dilectio est et scio quod sine dilectione esse non potes». ${ }^{101}$ Esta es la dimensión en la que se presentan los actos de conciencia, o, desde otro punto de vista, la perspectiva de la constitución del sí mismo. El alma conoce la realidad exterior, el mundo sensible, ${ }^{102} \sin$ embargo, el alma responde que ese conocimiento la ha engañado muchas veces ${ }^{103}$ y que, en lo visto y experimentado, no ha encontrado el amor permanente. De ahí la ausencia de felicidad del alma que se ve incapaz de conseguir lo que busca, que le causa una profunda desesperanza. ${ }^{104}$ Pero, al mismo tiempo, lo que percibe es miseria, finitud, e incapacidad de verse a sí misma. ${ }^{105}$ Estamos en el orden de la conciencia abierta a las realidades tanto exteriores como interiores. Lo que en primer lugar manifiesta el alma es el conocimiento de la realidad exterior y un mínimo conocimiento de sí

100 M. Heidegger, Estudios sobre mística medieval, FCE, México, 1997, p. 160: «sólo un hombre religioso puede comprender la vida religiosa, ya que, en otro caso, no dispondría de datos genuinos». Esta afirmación es presentada por Heidegger como una dificultad para el conocimiento de los actos de conciencia del hombre religioso desde una perspectiva puramente fenomenológica, tal como él entiende la fenomenología. Lo que he venido planteando es lo que afirma Heidegger, pero desde una perspectiva religiosa, ya que esa es la perspectiva de Hugo de San Víctor que sí dispone de datos genuinos.

101 DAA, PL 176,951. De aquí en más volveremos sobre algunos textos que ya hemos considerado pero no es posible evitar hacerlo.

102 DAA, PL 176, 952: «ecce tu novisti omnia, vidisti pene singula, experta plurima».

103 Ibid.: «Multis enim jam experimentis didici fallacem esse, et fugacem amorem hujus saeculi, quem semper, vel cum perit id quod mihi elegeram perdere, vel cum aliud, quod magis placeat, supervenerit, cogor commutare; sic adhuc desideriis incerta fluctuo, dum nec sine amore esse possum, nec verum amorem invenio».

104 Cfr. DAA, PL 176, 953.

105 Ibid.: «Certe si in rebus temporalibus, et quae videri possunt, verus et permanens amor non est, amari autem non potest, quod non potest videri, aeterna miseria semper viventem sequitur, si semper permanens amor non invenitur. (...) Oculus cuncta videt, seipsum non videt, et co lumine, quo reliqua cernimus, ipsam, in qua positum est lumen, faciem nostram non videmus». 
misma sobre todo por los efectos, es decir, siendo su vida principalmente amor, no encuentra el objeto permanente de ese amor. Esa permanencia del objeto la ve el alma como una necesidad ante la insatisfacción delante de la realidad externa a sí misma. De todos modos, según se ve en el entero diálogo, lo exterior admite varias significaciones. En un primer momento, lo externo son las cosas creadas, el mundo natural; pero según va avanzando el alma en el conocimiento de sí misma, llega, por una parte, a la percepción de su propia realidad, con todas las perfecciones que posee; en segundo lugar, percibe también su condición finita, su limitación y su culpa, pero esto delante de la percepción del Otro en el cual reconoce al autor del mundo y de sí misma.

La percepción, pues, no debe entenderse como mera sensación o impresión de las cosas materiales en el alma, sino que, aun existiendo aquella, la percepción se trueca también en una suerte de intuición de sí misma. «Ego igitur quia faciem meam et speciem vultus mei qualis sit, contemplari nequeo, facilius in ea, quae foris admiranda videntur, affectum dilectionis meae extendo»; ${ }^{106}$ es decir, este es el primer plano de advertencia de la realidad. Pero la búsqueda del amado le abre al alma otra forma de percepción no directa sino indirecta, a saber, verá y contemplará al amado en la misma medida en que ella se descubra a sí misma: y éste es un paso necesario ya que el alma no puede recibir el amor si ella misma no se conoce - no se advierte - como capaz de recepción de ese amor. El alma volcada a las realidades exteriores carece, pues, de una dimensión de autoconciencia para la cual es necesaria la percepción del mundo externo, pero no es suficiente; sin embargo, aquella primera percepción está de alguna manera señalando su capacidad para captar lo que le ha sido dado interiormente: «noluit (amantem) adhuc seipsum tibi presentare, sed munera misit, arrham dedit, pignus amoris, signum dilectionis». ${ }^{107}$ Nos encontramos con que, en efecto, no hay una presencia visible del amado, sí en cambio están los munera, el arrha, el pignus, el signum. De ahí que afirme Hugo: «dilige illum in donis illius, quod data sunt ab illo». ${ }^{108}$ Por eso responde el alma: «me video omnia in pignus dilectionis accepisse». ${ }^{109} \mathrm{El}$ discurso es, pues, eficaz en cuanto amplia el campo de percepción del alma que pasa de lo concreto material a lo simbólico, es decir, a un orden de realidad superior que se manifiesta y es percibida parcialmente con la suficiente claridad como para mostrar lo que se oculta en el mismo símbolo.

De allí que el alma se muestre en un estado bien diverso del primero: antes estaba en un estado de tristeza mientras que ahora declara: «verba tua inflammaverunt me, concepi ardorem, et aestuo intus». ${ }^{110} \mathrm{Ha}$ pasado de una situación en que la relación con la exterioridad la acuciaba y le provocaba un estado de pena, a otra situación, ahora interior, en la que advierte la presencia de un bien que sólo interiormente es perceptible y cuya posesión le causa un estado de ardor ante la cercanía del amado. Pero el alma advierte también que ese amor, como ya hemos visto anteriormente, le debe pertenecer a ella sola. De allí el discurso del hombre sobre el amor universal de Dios a todas las criaturas pero que concluye diciendo que ese amor común es a la vez singular: el alma es amada en sí misma, como sujeto único ya que la naturaleza del amor del amante es tal que no se reparte y mengua porque ama la totalidad de lo creado, sino que la infinitud de ese amor se manifiesta en el

106 DAA, PL 176, 954.

107 Ibid.

108 DAA, PL 176, 955-956.

109 DAA, PL 176, 956.

110 Ibid. 
sujeto individual: «satis jucundae mihi sunt assertiones tuae (...)», ${ }_{11}^{111}$ dice el alma de modo tal que «quanto plus audio, tanto plus audire concupisco (..)». ${ }^{12}$ Es decir, el alma ya percibe la realidad del amor que se manifiesta en los signos. De allí también que la posesión del amor hace declarar al alma ante la realidad de la culpa percibida: «O felix culpa, ad quam diluendam dum ille charitate trahitur, ipsa quoque ejus charitas mihi desideranti, et totis eam praecordiis concupiscenti aperitur» ${ }^{113} \mathrm{Es}$ decir, ante la presencia del amor tampoco la culpa del pecado vuelve al alma al primer estado de tristeza, sino que en la advertencia del perdón vuelve a ver el signo del amor. De aquí que nuevamente el alma declare: «vere fateor merito amor iste singularis dicitur, qui, cum se in multos diffundat, ita tamen unice singulos amplexatur». ${ }^{114} \mathrm{Y}$ continúa el alma: «ego autem fateor (...) quod illum, cui tam vehementer placere cupio, ubique mihi praesentem et omnia mea occulta videntem intueor», ${ }_{115}^{15}$ es decir, la presencia del amado ( $u b i q u e$ ) hace que el alma pueda ver lo que antes le estaba oculto: se trata así de una nueva percepción de sí misma mediante la cual «subito innovor et tota immutor ${ }^{116}$ aunque el amado, como hemos citado anteriormente, se presenta invisible, oculto, incomprehensible; sin embargo el alma puede conocerlo - por el amor-, amarlo, seguirlo, aprehenderlo y poseerlo. Así, de la percepción de la pura exterioridad, Hugo ha conducido el diálogo hasta la percepción de la interioridad y, en ella, la percepción del amor y del objeto amado.

\section{c) La reflexión y el descubrimiento del Tú}

1. Según lo que llevamos expuesto sobre el conocimiento que el alma adquiere de sí misma, tal como presenta la cuestión Hugo de San Víctor, aparece con claridad que el procedimiento seguido por nuestro autor es un procedimiento dialógico, no solamente en cuanto el texto se presenta en forma de diálogo - lo cual también es significativo-, sino sobre todo porque los dialogantes dialogan entre sí y con la realidad que en un primer momento se presenta escondida y luego aparece a la conciencia. No hay en el texto una teoría de la reflexión formulada de modo teórico, sino, más bien, una reflexión sobre el sí mismo que tiene carácter esencialmente relacional. La finalidad del diálogo no es la pura autoconciencia, sino el conocimiento y el amor subsiguiente de una realidad que entra en relación con la conciencia. A su vez, esta conciencia es conciencia de un sujeto que manifiesta una unidad psíquica: desde un punto de vista metafísico-antropológico nos encontramos con el hombre en su unidad de cuerpo y alma, y es él el que reflexiona sobre su propia realidad con la finalidad de encontrar fuera de sí una realidad que constituya y organice su interioridad. Pero esta realidad externa no es mera exterioridad, sino que en la reflexión el sujeto ve que ya se encuentra de algún modo dentro de sí. El paso posterior es la apertura completa a esa realidad fuera de sí, lo cual genera que tal realidad pase a formar parte de su propia interioridad. De este modo, la unidad sustancial se articula con una unidad que podríamos denominar operativa: el sujeto agente es una unidad sustancial, pero a través de la reflexión descubre que posee una serie de actos que le permiten hacerse con una exterioridad que, en el momento en que es poseída, deja de ser una pura obje-

\footnotetext{
111 DAA, PL 176, 959.

112 DAA, PL 176, 961.

113 DAA, PL 176, 962.

114 DAA, PL 176, 968.

115 Ibid.

116 DAA, PL 176, 970.
} 
tividad para transformarse en parte de sí mismo. De aquí que el signo, el arrha, que es interior al hombre lo conduce, por un lado, a un movimiento de apertura, y por otro, pero en una esencial unidad, a un movimiento circular de visión de sí mismo, de reconocimiento de la realidad que se presenta como signo en la subjetividad, para volver a ésta con aquella realidad que ya no es más signo sino adquisición subjetiva. Sin embargo, este círculo no se cierra completamente sobre sí mismo ya que la intencionalidad del amor y del conocimiento incluyen en ese proceso la captación constante de la subjetividad que ama y conoce algo que no es ella misma. ${ }^{17}$ La apertura del círculo es esencial para la vida anímica. ${ }^{118}$

2. La filosofía moderna ${ }^{119}$ presenta una concepción del sujeto, y por ende, del conocimiento y de la reflexión, diversa a la que presenta Hugo de San Víctor. En Descartes el punto de partida de la filosofía, como es bien sabido, se encuentra en el cogito. Por otra parte, la unidad del hombre es para Descartes un problema que no encuentra solución: res extensa y res cogitans son dos modos sustanciales que, por así decir, conviven en el hombre. De aquí que el objeto principal del cogito es el esclarecimiento de la subjetividad, del mundo y de Dios a través de la crítica eidética. El programa lo enuncia así Descartes: «será necesario comenzar por el alma racional, porque es en ella donde reside todo nuestro conocimiento; y una vez considerada su naturaleza y sus efectos, consideraremos a su autor; y después de haber conocido que Él es y cómo ha creado todas las cosas que están en el mundo, veremos atentamente aquello que hay de más cierto en lo que respecta a las otras criaturas, y examinaremos de qué manera nuestros sentidos reciben los objetos y cómo nuestros pensamientos pueden ser verdaderos o falsos». ${ }^{120}$ Estas ideas programáticas tienen un criterio subyacente que es el de la duda, ${ }^{121}$ es decir, el inicio de la filosofía comienza por el análisis de la razón que posee ideas, las cuales deben someterse a la duda a fin de ver si esas ideas resisten a la crítica, es decir, si son claras y distintas. Y declara Descartes que después de haber estudiado mucho en los libros y después de haber fijado su atención «en el libro del mundo (...)» que «un día tomé la reso-

117 Afirma Santo Tomás, In IV Sent., d. 49, q.1, a.2: «beatitudo creata quae in nobis est non diligitur nisi dilectione concuspicientiae; unde eius dilectione referimus ad nos et per consequens referimus eam in Deum, cum et nos in Deum referre debeamus». De alguna manera sintetiza el camino seguido por Hugo: la búsqueda de la felicidad comienza en el sujeto pero no permanece en él, sino que se orienta y se relativiza en el sentido de que no es en nosotros mismos donde se resuelve la relación amorosa sino en la relación al Absoluto. Se trata de una doble dimensión que, sin embargo, constituye una unidad.

118 J. De Finance, Le 'cercle' de la connaissance et du vouloir à propos d'un texte de Saint Thomas, en L'ouverture et la norme. Questions sur l'agir humain, Libreria Editrice Vaticana, Città del Vaticano, 1989, p. 3: «Ce 'cercle' pourtant, ne signifie nullement un retour au point initial. Le sujet est devenu sujet connaissant et aimant; l'objet est devenu objet connu et aimé. Le mouvement de l'amour ou du désir n'annulle aucunement celui de la connaissance: il le complète. L'intelligence déploie l'objet selon la ligne de la vérité, la volonté et l'amour selon la ligne de la valeur. Car la fin n'est fin en acte que dans et par le mouvement qu'elle déclenche et la valeur ne 'vaut' pleinement que lorsqu'elle est valorisée, lorsqu'elle provoque l'amour et le desin».

119 Consideraremos de modo sucinto dos posturas sobre la subjetividad, la de Descartes y la de Fichte. Para una exposición más amplia me permito remitir a mis trabajos, D.O. Gamarra, Esencia y objeto, Peter Lang, Berna, 1990, esp. pp. 237-322; J.G. Fichte: l'affermazione dell'Assoluto, Acta Philosophica, III/2 (1994), pp. 247-269; número monográfico: Dio nella filosofia Moderna; y, Ragione critica e nostalgia di Dio, en I. Yarza (ed.) Atti del V Convegno di Studio: Immagini dell'uomo. Percorsi antropologici nella filosofia moderna, Pontificia Universidad Pontificia de la Santa Ciuz, 29 febrero- $1^{\circ}$ marzo 1996, Armando Editore, Roma, 1997, pp. 39-62.

120 R. Descartes, La Recherche de la vérité par la lumière naturelle, ed. Adam-Tannery (AT), vol. X, p. 505, Vrin, París, 1974-1983.

121 Se discute sobre el carácter metódico de la duda; no entramos en el tema ya que nos basta su afirmación en Descartes como criterio veritativo. 
lución de estudiar también en mí mismo». ${ }^{122}$ De allí el inicio de la reflexión. Sin duda, no nos encontramos con un místico, como en el caso de Hugo de San Víctor, pero sí con un filósofo que hace de la reflexión sobre sí mismo y sobre los contenidos eidéticos el centro de la filosofía. El resto de los temas enunciados en el texto citado de La Recherche son posteriores desde el punto del principio que constituye la reflexión y, también, cronológicamente. El cogito cartesiano revela, como es bien sabido, el sum, es decir la existencia subjetiva: esta inferencia tiene un indudable valor antropológico y existencial; sin embargo, la reflexión cartesiana se vuelca no tanto al análisis existencial, sino por el contrario al esclarecimiento de los contenidos eidéticos según los criterios de claridad y distinción. Este es, desde un punto de vista histórico, el punto de partida de la constitución moderna de la subjetividad: el yo es pensante y su ser se constituye en el cogito que, a través de la duda, puede llegar al conocimiento de la verdad: «si una sola vez en la vida procuramos dudar de todo», ${ }_{1} 23$ dice Descartes, entonces estaremos en condiciones de alcanzar la verdad ya que la duda «se ordena a la sola contemplación de la verdad». ${ }^{124}$

Con estas breves consideraciones, estamos en condiciones de afirmar que la reflexión cartesiana, si bien infiere el valor existencial del sum, se centra en la sola subjetividad pensante: ella es, en efecto, el centro que constituye lo verdadero de tal modo que «sentire, imaginare, et pure intelligere, sunt tantum diversi modi percipiendis, ${ }^{125}$ es decir, la percepción que habitualmente se considera como un contacto sensible con algo fuera del sujeto, reúne en Descartes no solamente el sentir, sino también el imaginar y, de modo más radical, el puro entender. Así la idea es pensamiento sin más, y pensamiento es todo aquello que de tal manera está en el sujeto que el sujeto es inmediatamente consciente de la idea clara y distinta. ${ }^{126}$ No hay, pues, lugar en la reflexión cartesiana, espacio para otra cosa que no sean las ideas y, a partir de ellas, se puede llegar tanto a la existencia de Dios como a la existencia del mundo. El dato originario es pensamiento-idea, que se identifica con la esencia de la subjetividad. Lo dado es dudoso, se debe escrutar según un criterio de claridad y distinción. Así, se presenta clara la diferencia con la reflexión del Victoriense en quien los datos de la conciencia no pasan por el tamiz de la duda, sino por un criterio de confrontación dialógica con la alteridad, al mismo tiempo que lo que el sujeto encuentra en sí mismo es entendido como donación ante la cual también el sujeto se dona. El problema ético cartèsiano, y el problema de las pasiones, constituyen un punto de toque respecto a la limitación de la reflexión. Ninguno de los dos temas tienen verdadera solución en Descartes, ya que tanto la ética como la cuestión de las pasiones implican la unidad del hombre y, a la vez, un horizonte receptivo de la subjetividad que Descartes no admite. ${ }^{127}$

3. En Fichte nos encontramos con una noción de subjetividad que, dependiendo de Descartes y de Kant, se radicaliza: de Descartes retoma el cogito, que lo interpreta como esència de la subjetividad; pero, por otra parte, critica la noción kantiana de noúmeno: ya que éste no es cognoscible,

122 R. Descartes, Discours de la méthode, AT, VI, 10.

123 R. Descartes, Principia philosophiae, I, 1; AT VIII-1, 5.

124 R. Descartes, Principia philosophiae, I, 3; AT, VIII-I, 5.

125 R. Descartes, Principia philosophiae, I, 32; AT, VIII-1, 17.

126 Cfr. R. Descartes, Méditations métaphysiques, 2da. respuesta; AT, IX-1, 124.

127 Sobre estos temas, cfr. A. Malo, Certezza e volontà. Saggio sull' 'etica cartesiana, Armando Editore, Roma, 1994, y del mismo autor, Antropología dell'affettività, Armando Editore, Roma, 1999, esp. pp. 19-66. 
afirma Fichte, tampoco se puede afirmar. Por lo tanto la única realidad de la cual tenemos absoluta certeza es la del sujeto pensante. ${ }^{128}$ Lo que intenta Fichte seguidamente es la deducción de todos los actos anímicos a partir de la primera realidad del yo pensante: en esa deducción llega también a los actos de la sensibilidad. Así como considerábamos antes que el punto de partida de Descartes es la razón, en Fichte ocurre lo mismo aunque de modo más radical, es decir, no niega la realidad del conocimiento sensible, pero no puede estar cierto de la actividad sensible y de su objeto, si estos no han sido deducidos del yo puro. Sin embargo, Fichte también intenta una salida hacia el Absoluto: su punto de partida no es el mundo creado, sino las realizaciones parciales del saber y de la Iibertad. Si existe el saber limitado y realizaciones limitadas de la libertad, debe haber un Absoluto en quien ese saber y esa libertad se den de manera infinita. Pero el hombre, por su condición finita, no puede llegar sino hasta el límite de su actividad primera, que es unión de pensamiento y libertad, y allí afirmar la existencia del Absoluto, no desde el punto de vista del Absoluto sino desde el punto de vista finito. De ese modo, Fichte afirma la existencia del Absoluto pero niega su conocimiento: no se puede afirmar nada del Absoluto sino que es puro Absoluto; ${ }^{129}$ el hombre finito tiende a él con un esfuerzo de razón y libertad de carácter casi infinito (undenliches Streben), pero sólo llega a contemplar la imagen del Absoluto en la subjetividad como realización del saber y de la libertad finitas. Todo este camino, apenas esbozado aquí, se realiza por vía de reflexión sobre la propia realidad del yo. De este modo, la reflexión es el instrumento que lleva a deducir la actividad del yo y su relación con el mundo externo; pero se trata de una vía racionalística que no parte de los datos de la relación hombre-mundo, sino que esta relación debe ser deducida a partir de un principio primero constituido por la realidad del yo pensante. El tema de la reflexión en Fichte es de sumo interés antropológico aunque tiene la limitación de moverse, como en Kant, en el horizonte de la filosofía trascendental. No se trata, pues, de una verdadera fenomenología que toma datos de la experiencia, sino de la afirmación de una primera evidencia a partir de la cual se va construyendo la realidad del yo. De todos modos en Fichte hay un momento receptivo por parte de la sensibilidad y de la racionalidad, pero el criterio último es la certeza y claridad del pensamiento. En este sentido, la filosofía de Fichte no asume el misterio del ser, sino que se frena en el límite de ese misterio.

4. El camino de la filosofía moderna tiene varios puntos de inflexión crítica, sobre todo por lo que se refiere a la crítica de la concepción de la racionalidad y de la subjetividad como autonomía y perfecta autotrasparencia, es decir, la concepción de la esencia de la subjetividad como pensamiento. En el siglo XX nacen algunas corrientes de pensamiento que, además de la crítica a esos elementos de la modernidad, proponen de modo positivo una nueva concepción de la subjetividad. Ésta no es concebida como puro pensamiento sino que, acorde con la unidad sustancial del hombre, la subjetividad se considera de un modo más rico y profundo. En nuestra época se ha presentado la

128 J.G. Fichte, Die Principien des Gottes-Sitten- und Rechtslehre, F. Meiner Verlag, Hamburgo, 1986, p. 96: «Se pone este principio [el yo pensante] en la génesis de la razón: yo pregunto, cuál es su premisa absoluta: claramente: el pensamiento que no es puramente inmanente, sino que se actualiza a través de un principio análogo: el deber». Ya años antes había afirmado, Grundlage der gesamten Wissenschaftslehre, F. Meiner Verlag, Hamburgo, 1988, p.16: «así, la posición del Yo a través de sí mismo es en sí mismo un hecho puro. - El Yo se pone a sí mismo, y él es, quiere este puro ponerse a través de sí mismo (...)». Para estas cuestiones, cfr. R. Lauth, La filosofia trascendentale di J.G. Fichte, Guida Editori, Nápoles, 1986.

129 Sobre este punto son de primera importancia las Wissenshaftslehre de 1801 y de 1804. Cfr. W. Janke, Fichte. Sein und Reftexion. Gundlagen der kritischen Vermunft, Walter de Gruyter, Berlín, 1970. 
dicotomía entre individualismo y colectivismo. El primero tiene sus raíces en la concepción Ilustrada del hombre y el segundo, como fruto de la crítica al individualismo, tiende a reducir al hombre a la especie humana: una suerte de humanidad donde hay una absoluta igualdad y donde el individuo desaparece. Pero «el hecho fundamental de la existencia humana no es ni el individuo en cuanto tal ni la colectividad en cuanto tal. Ambas cosas, consideradas en sí mismas, no pasan de ser formidables abstracciones. El individuo es un hecho de la existencia en la medida en que entra en relaciones vivas con otros individuos; la colectividad es un hecho de existencia en la medida en que se edifica con vivas unidades de relación». ${ }^{130}$ Estas palabras de Buber nos acercan nuevamente a la concepción de la subjetividad relacional que hemos podido ver en los textos de Hugo de San Víctor: el individuo se constituye por una relación interpersonal, de allí le llegan los datos genuinos de lo que él mismo es y, al mismo tiempo, la constitución del sí mismo depende de la percepción de esta relación interpersonal. Buber tematiza de modo explícito la cuestión del entre como categoría relacional entre personas, y así «más allá de lo subjetivo, más acá de lo objetivo, en el «filo agudo» en que el «yo» y el «tú» se encuentran se halla el ámbito del "entre"». ${ }^{131}$ En efecto, el tú es un componente esencial del yo que no se define por su soledad y autonomía sino por su carácter relacional: hay evidentemente un núcleo esencial individual de constitución de la propia persona tanto a nivel ontológico como a nivel práctico, pero tanto uno como otro no llevan al aislamiento de la persona sino que, por el contrario, la persona se «hace» relacionalmente. Por eso, tanto el conocimiento de sí mismo y el amor son dos facetas de la misma realidad personal: el conocimiento personal no es encerramiento sino descubrimiento de la apertura esencial de la persona que se da en la forma primaria de donación amorosa. «El mundo del Ello [lo impersonal] está engastado en el contexto del espacio y del tiempo. El mundo del Tú no está engastado ni en el contexto del espacio ni en el tiempo. Tiene su coherencia en el Centro, donde las líneas prolongadas de las relaciones se encuentra en el $T u ́$ eterno». ${ }^{132}$ La relación interpersonal, pues, es esencial en la constitución de la persona. ${ }^{133}$

El pensamiento místico, lejos de presentarse como una forma de reflexión que tiende al aislamiento del individuo, propone un crecimiento de la totalidad de la persona de modo relacional, es decir, en la dialogicidad con un tú que en el caso de la mística es el Tú eterno. En esa relación el místico no abandona la realidad circundante - el mundo, las otras personas; la sociedad-, sino que la asume de un modo diverso marcado esencialmente por la relación con el Tú eterno. De allí que no desprecia ni el conocimiento de sí mismo, ni el conocimiento personal, sino que necesita de ellos

130 M. Buber, ¿Qué es el hombre?, FCE, Buenos Aires, 1992, p. 146.

131 M. Buber, ibid., p. 189.

132 M. Buber, Yo y Tú, Ediciones Galatea, Buenos Aires, 1960, p. 94. Y sigue poco más adelante: «el mundo de la relación se construye en tres esferas. La primera es nuestra vida con la naturaleza; en ella la relación llega hasta el umbral del lenguaje. En la segunda esfera, la de nuestra vida con los hombres, la relación adquiere la forma del lenguaje. La tercera esfera es nuestra vida con las formas inteligibles; la relación se produce en ella sin lenguaje, pero engendra un lenguaje. En cada una de estas esferas, a través de todo el proceso de llegar a ser, cuya presencia sentimos, tendemos la mirada a la franja del Tú eterno; en cada Tú nos dirigimos al Tú eterno. Todas estas esferas están incluidas en el Tú eterno, pero él no está incluido en ninguna» (p. 95).

133 En este sentido son importantes los trabajos de Edith Stein, sobre todo Das Problem des Einfïhlung. Cfr. E. Bernbeck, Individulum und Gemeinschaft bei Edith Stein, Carmelus, 14 (1967), pp. 3-62; también, L. Vigone, Il pensiero filosofico di Edith Stein, Città Nuova, Roma 1973. 
para asumirlos en esa relación particular que tiene con Dios a través de un lenguaje nuevo - como se expresaba Buber - que se crea y nace en esa relación. Por eso las relaciones religiosas fundamentales son de índole cognoscitivo-afectivo y se originan no solamente en la conciencia clara y distinta (como en el modelo cartesiano), sino en un estrato más profundo de ella. Estas experiencias son conocimiento de sí mismo, conocimiento del objeto y tienen también una clara índole afectiva: el gozo, el poder, el sentimiento de estar ligado a algo de mayor magnitud que el hombre, que actúa en el universo y constituye el supremo refugio.

\section{A MODO DE CONCLUSIÓN}

El recorrido que hemos hecho del texto de Hugo de San Víctor, nos ha permitido identificar algunos aspectos del conocimiento del sí mismo a través de una reflexión mística. No hemos pretendido sistematizar todos los aspectos que han ido apareciendo a lo largo del texto a modo de una teoría, sino que nos hemos atenido al aparecer de los hechos mismos sin subsumirlos en una categorización rígida. Esta es una tarea que se puede realizar sin duda, pero ello alejaría el carácter directo y si se quiere espontáneo que presenta el texto de Hugo hacia una región que no está en el espíritu del texto. Si se quiere, este es un trabajo de presentación, es decir, de recopilación del material elemental de la experiencia mística: la reflexión sistemática corresponde a un segundo momento en el que necesariamente se perdería la inmediatez fenomenológica en la que los hechos cognoscitivos y apetitivos de la vida relacional van apareciendo en el texto de Hugo.

Por otra parte, si se quisiera hacer una teorización más completa del conocimiento del sí mismo, habría que tomar en consideración otros textos místicos y teológicos de nuestro autor, lo cual excede los objetivos propuestos en estas páginas.

Concluimos, pues, el presente trabajo que se ha movido en el campo de la antropología y de la teología antropológica, con la certeza de que el tema propuesto requiere un proseguimiento y una profundización, ya que el pensamiento de Hugo de San Víctor lo merece por la riqueza y amplitud de sus temas e intereses.

Daniel O. Gamarra

Paraguay, 1114, 1

1057 - Buenos Aires (Argentina) 